\title{
Digital Full-Scope Simulation of a Conventional Nuclear Power Plant Control Room, Phase 2: Installation of a Reconfigurable Simulator to Support Nuclear Plant Sustainability
}

Ronald Boring, Vivek Agarwal, Kirk Fitzgerald, Jacques Hugo, Bruce Hallbert

March 2013

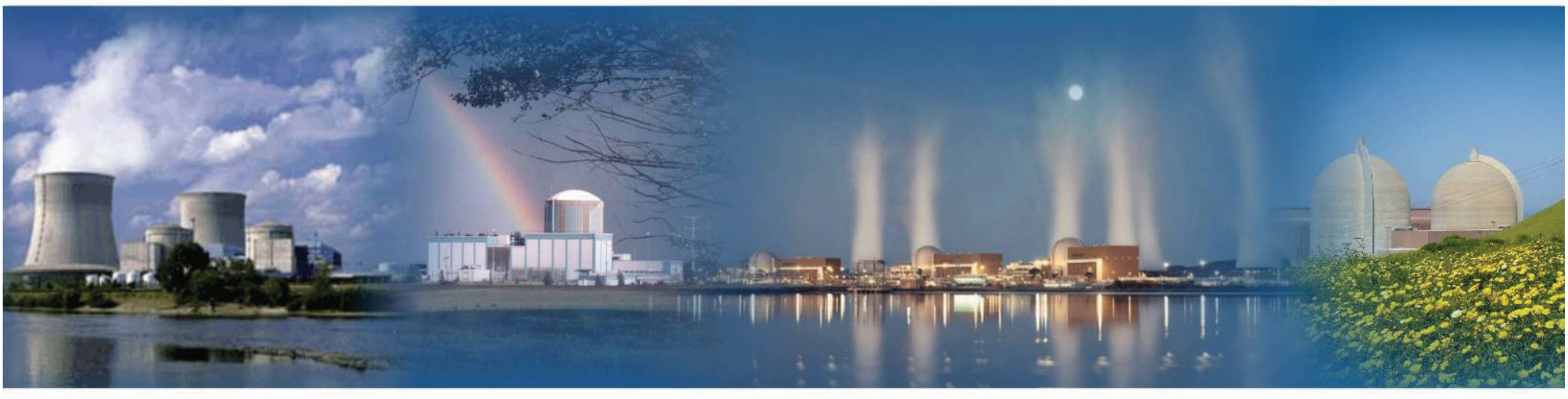

The INL is a U.S. Department of Energy National Laboratory operated by Battelle Energy Alliance 


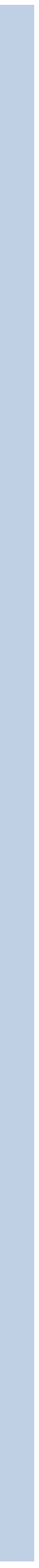




\section{DISCLAIMER}

This information was prepared as an account of work sponsored by an agency of the U.S. Government. Neither the U.S. Government nor any agency thereof, nor any of their employees, makes any warranty, expressed or implied, or assumes any legal liability or responsibility for the accuracy, completeness, or usefulness, of any information, apparatus, product, or process disclosed, or represents that its use would not infringe privately owned rights. References herein to any specific commercial product, process, or service by trade name, trade mark, manufacturer, or otherwise, does not necessarily constitute or imply its endorsement, recommendation, or favoring by the U.S. Government or any agency thereof. The views and opinions of authors expressed herein do not necessarily state or reflect those of the U.S. Government or any agency thereof. 



\section{Digital Full-Scope Simulation of a Conventional Nuclear Power Plant Control Room, Phase 2: Installation of a Reconfigurable Simulator to Support Nuclear Plant Sustainability}

Ronald L. Boring, Vivek Agarwal, Kirk Fitzgerald, Jacques Hugo, Bruce Hallbert

March 2013

Idaho National Laboratory

Idaho Falls, Idaho 83415

http://www.inl.gov

Prepared for the

U.S. Department of Energy

Office of Nuclear Energy

Under DOE Idaho Operations Office

Contract DE-AC07-05ID14517 



\section{EXECUTIVE SUMMARY}

The U.S. Department of Energy's Light Water Reactor Sustainability program has developed a control room simulator in support of control room modernization at nuclear power plants in the U.S. This report highlights the recent completion of this reconfigurable, full-scale, full-scope control room simulator buildout. The simulator is fully reconfigurable, meaning it supports multiple plant models, including those developed by different simulator vendors. The simulator is full-scale, using glasstop touch-sensitive panels to digitally display the analog control boards found in existing plants. The present installation features 15 glasstop panels that are linked together, uniquely achieving a complete control room representation. To the authors' knowledge, this is the largest single installation of glasstop panels in the world. The simulator is also full-scope, meaning it uses the same thermal-hydraulic and physically simulated plant models used by training simulators found at operating nuclear power plants. Unlike in the plant training simulators, their deployment on glasstop panels allows a high degree of customization of the panels, allowing the simulator to be used for research on design issues of new digital control systems for control room modernization.

Control room modernization goes beyond like-for-like replacement of analog instrumentation with digital control systems. The simulator is being used to design additional functionality that enhances operator control and awareness such as:

- Access important trend information to allow the operators better to understand emerging conditions,

- Perform calculations that must otherwise be done manually by the operators,

- Provide prioritized alarm lists that help the operators respond more quickly to transients,

- Provide helpful checklists to augment paper-based control room procedures, and

- Automate previously manually performed actions.

This report includes separate sections discussing the glasstop panels, their layout to mimic control rooms of actual plants, technical details on creating a multi-plant and multi-vendor reconfigurable simulator, and current efforts to support control room modernization at U.S. utilities. The glasstop simulator provides an ideal test bed for prototyping and validating new control room concepts. Equally importantly, it is helping create a standardized and vetted human factors engineering process that can be used across the nuclear industry to ensure control room upgrades maintain and even improve current reliability and safety. 


\section{ACKNOWLEDGMENTS}

The funding for the control room glasstop simulator buildout was made possible through funding from the U.S. Department of Energy (DOE) Light Water Reactor Sustainability (LWRS) Program. We are grateful to Richard Reister of the DOE and Kathryn McCarthy and Ken Thomas of the Idaho National Laboratory (INL) for championing this effort. The first phase of the control room simulator buildout at the INL was made possible through an agreement between Battelle Energy Alliance (operator of the INL for the United States Department of Energy), Southern California Edison Company (parent company of San Onofre Nuclear Generating Station, SONGS), and L-3 MAPPS Corporation (simulator vendor). We are grateful to Gerald Wyatt (Simulator Manager at SONGS), Vincent Gagnon (Sales Manager for L-3), John Micks (Project Manager for L-3) and their staff for their hard work in making the acquisition of the SONGS simulator possible. The second phase of the control room simulator incorporated the plant model from the Shearon Harris Nuclear Plant. From Duke Energy Progress, we especially thank Matt Gibson (Project Manager for Duke Energy Progress) and Mac McDade (Simulator Manager) for their assistance in installing the Harris Nuclear Plant simulator. We would also like to thank Steven Freel of GSE Systems, Inc., and his staff for their support of the cross-platform simulator buildout. Finally, we thank Brandon Rice and Nic Johnson for their expert support in assembling the software and hardware infrastructure used by the simulator, and to Chris Morgan for taking the simulator photographs included in this report. 


\section{CONTENTS}

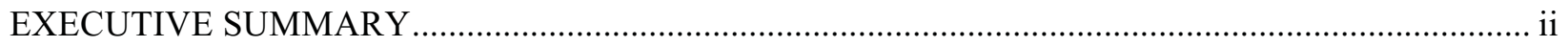

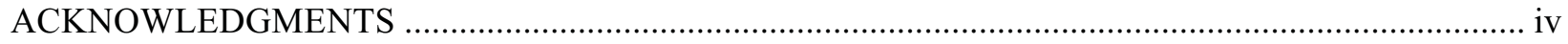

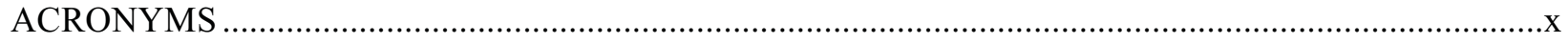

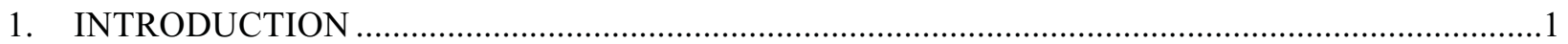

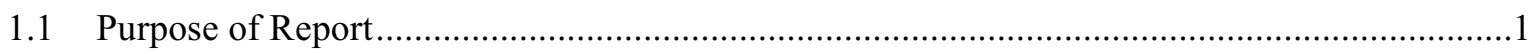

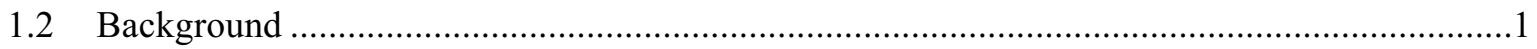

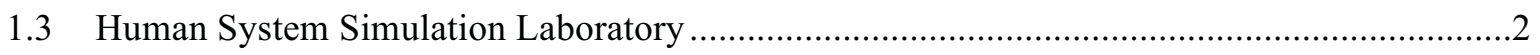

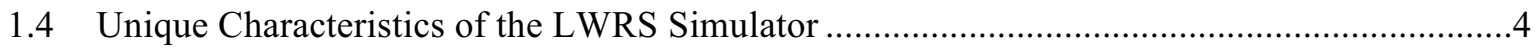

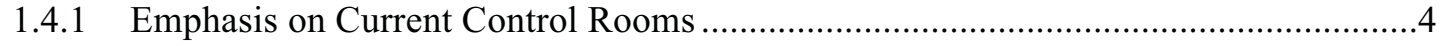

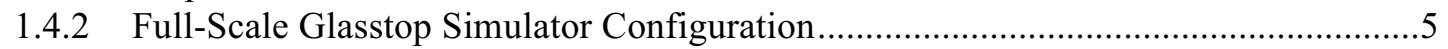

1.4.3 Configurability Between Multiple Plants ...................................................................6

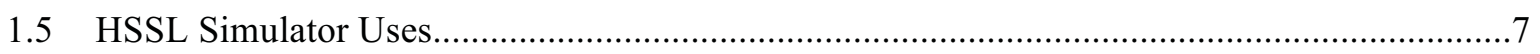

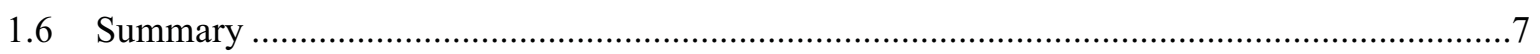

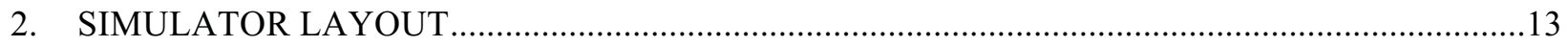

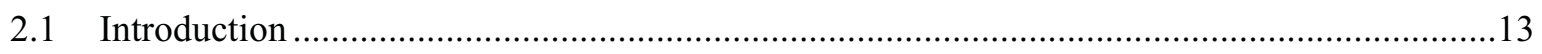

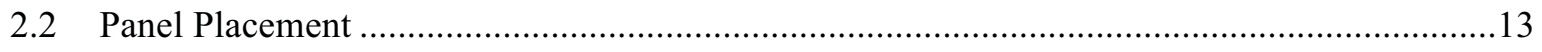

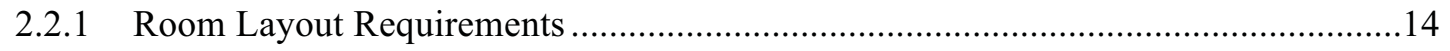

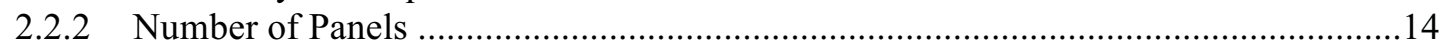

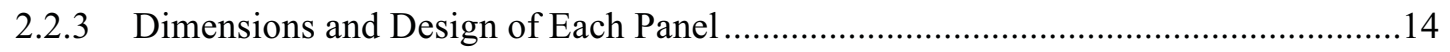

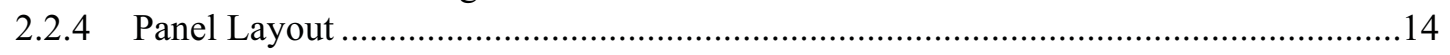

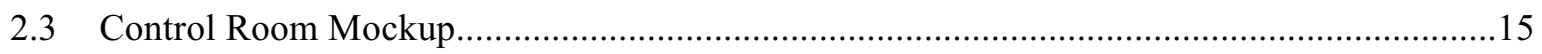

2.4 Configuring the HSSL for different Control Rooms.......................................................18

3. A CONFIGURABLE HARDWARE AND SOFTWARE ARCHITECTURE ...................................23

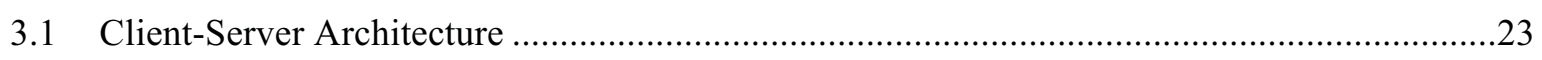

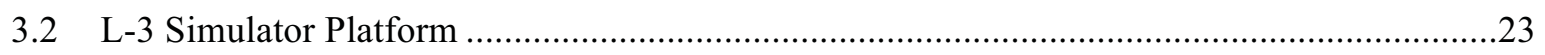

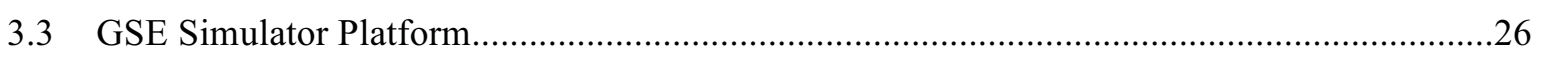

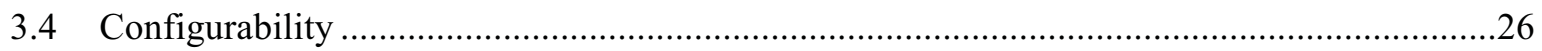

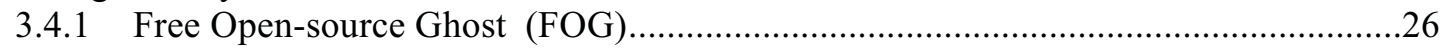

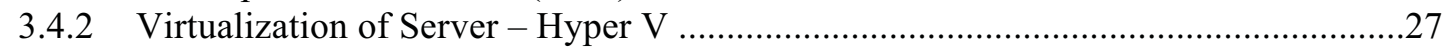

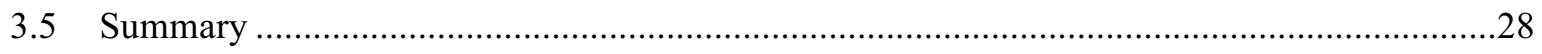

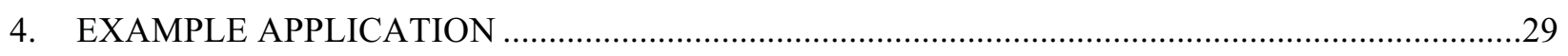

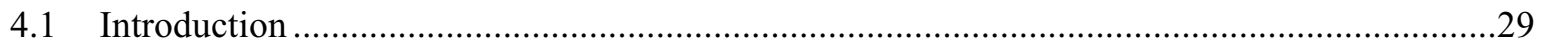

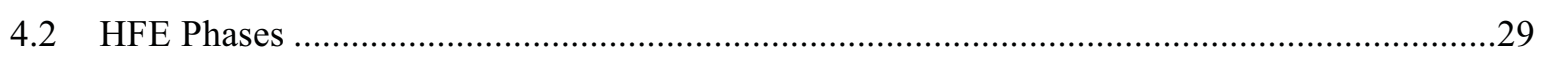

4.3 Simulator Use in the Function Analysis and Allocation and Task Analysis Workshop ..........31

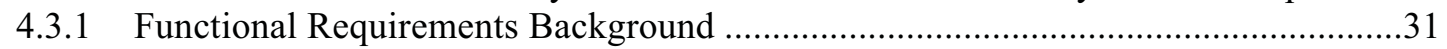

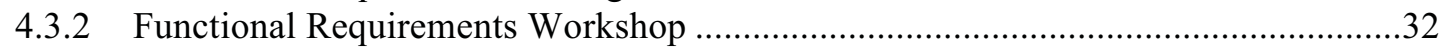




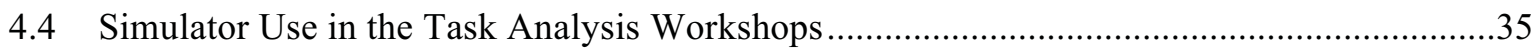

4.5 Moving Forward: Design, Verification and Validation, and Implementation Phases ..............38

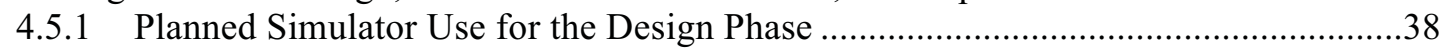

4.5.2 Planned Simulator Use in Verification and Validation .............................................42

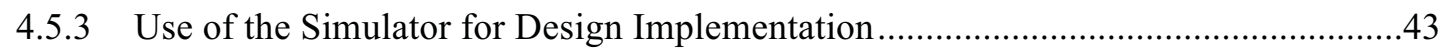

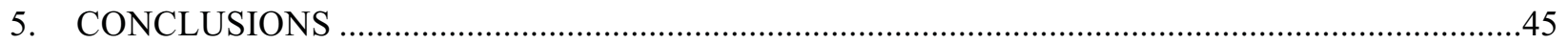

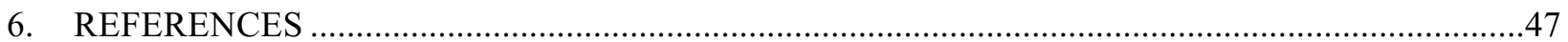




\section{FIGURES}

Figure 1. Reactor Operators Using the Glasstop Simulator in the HSSL ............................................ 2

Figure 2. The Full-Scale Layout of the HSSL Glasstop Simulator. ........................................................ 6

Figure 3. Summary of the Pilot Projects for the LWRS II\&C Systems Technologies R\&D

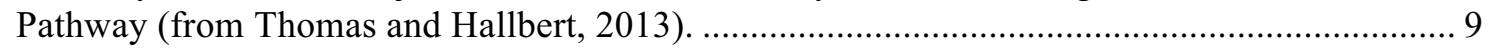

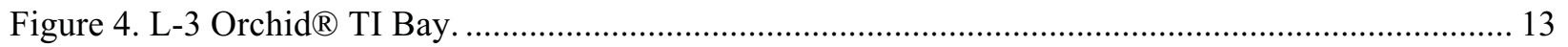

Figure 5. Common Control Room Layouts: (a) Horseshoe and (b) L-Shaped....................................... 15

Figure 6. Three-Dimensional Schematic Representations Used in Planning the Layout of the

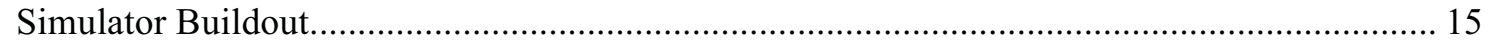

Figure 7. A Schematic Representation of the HSSL Simulator Layout.................................................. 16

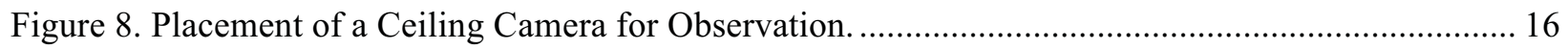

Figure 9. Mobile Camera Views of Staff in the HSSL Simulator. ............................................................. 17

Figure 10. Mapping of (a) Control Boards to (b) the Glasstop Panels on an L-3 Configuration. .............. 18

Figure 11. Mapping of the Reactor Support Panel CR57 on Three Glasstop Panels. .............................. 19

Figure 12. Mapping of (a) Control Boards to (b) the Glasstop Panels on a GSE Configuration................ 20

Figure 13. Screenshot of a Panel with Portions of Control Systems and Alarms Not Displayed.............. 20

Figure 14. A Schematic Representation of L-3 MAPPS' Client-Server Network Setup. ........................ 23

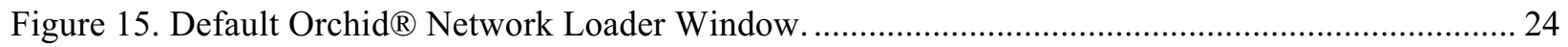

Figure 16. Orchid $\mathbb{R}$ Network Loader with Different Simulator Options................................................ 25

Figure 17. Controls on Panel CR57 Displayed on Three Different L-3 Panels Using the L-3 Hive

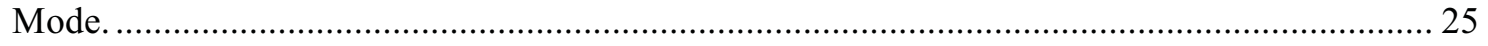

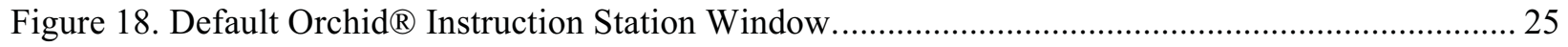

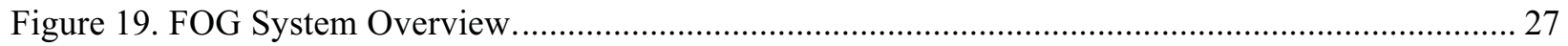

Figure 20. The LWRS Simulator Configuration Used for the FRA/FA Workshop. ................................ 32

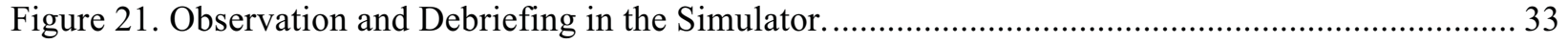

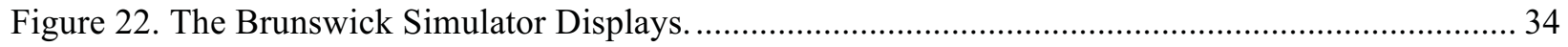

Figure 23. Sample Operational Sequence Diagram for a Simulator Scenario......................................... 36

Figure 24. Actual Training Simulators Modeled on the Glasstop Panels................................................ 36

Figure 25. Flow Diagram for Developing New HSI Displays for the DCS. ......................................... 40 


\section{TABLES}

Table 1. Control Room Research Simulator Characteristics (as of February 2013)............................... 8

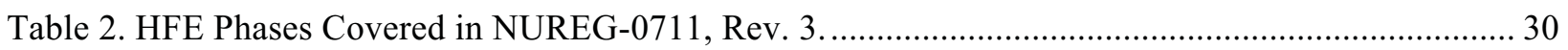

Table 3. Main Phases of Human Factors Engineering and Underlying Goals. ........................................ 31

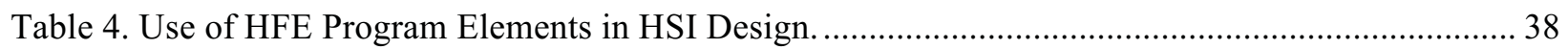




\section{ACRONYMS}

CAER

CAES

CFR

CR

CVCS

DCS

DOE

EPRI

ERFIS

EROB

FA

FOG

FRA

GE

gPWR

HFE

HRA

HSI

HSSL

IAEA

II

II\&C

IS

INL

ISV

I\&C

JADE

LCD

LWRS

NI

NL

NPP

NRC

OECD

OPC

OSU

PPC

PXE

R\&D

SONGS

TCS

TFTP

UCF

VDT

V\&V

WSC
Center for Advanced Energy Research

Center for Advanced Energy Studies

Code of Federal Regulations

Control Room

Chemical Volume Control System

Digital Control System

Department of Energy

Electrical Power Research Institute

Emergency Response Facility Information System

Engineering Research Office Building

Function Allocation

Free Open-Sourced Ghost

Functional Requirements Analysis

Graphics Environment

Generic Pressurized Water Reactor

Human Factors Engineering

Human Reliability Analysis

Human-System Interface

Human System Simulation Laboratory

International Atomic Energy Agency

In-core Instrumentation

Instrumentation, Information and Control Systems

Instruction Station

Idaho National Laboratory

Integrated System Validation

Instrumentation and Controls

Java Application Development Environment

liquid crystal display

Light Water Reactor Sustainability

Nuclear Instrumentation

Network Loader

Nuclear Power Plant

U.S. Nuclear Regulatory Commission

Office of Economic Cooperation and Development's

OLE for Process Control server

Ohio State University

Plant Process Computer

Preboot eXecution Environment

research and development

San Onofre Nuclear Generating Station

Turbine Control System

Trusted File Transfer Protocol

University of Central Florida

Visual Display Terminal

Verification and Validation

Western Services Corporation 


\section{INTRODUCTION}

\subsection{Purpose of Report}

This report builds on work summarized in a previous report entitled Digital Full-Scope Mockup of a Conventional Nuclear Power Plant Control Room, Phase 1: Installation of a Utility Simulator at the Idaho National Laboratory (Boring et al., 2012). That report provided the technical rationale for acquisition of a nuclear power plant (NPP) training simulator for use in research to support control room modernization. It also outlined the first steps in acquiring a full-scope plant simulator. Since the issuance of that report, additional progress has been made at the Human System Simulator Laboratory (HSSL) at the Idaho National Laboratory (INL) to create a high fidelity control room research and development capability. This simulator facility has now been used for research applications, and the lessons learned from those applications are being documented. Finally, new directions for research have been identified. Thus, this report documents new developments and insights on control room simulators for research since the previous report.

\subsection{Background}

With license extensions for most NPPs from the original 40-year license to now 60 years, crucial parts of the plants that were nearing end of life must now be replaced or modernized. Helping plants meet the needs of life extension is the key focus of the U.S. Department of Energy's (DOE) Light Water Reactor Sustainability (LWRS) program. Within this framework, the DOE is working closely with utilities to address many of the challenges associated with control room modernization. Utilities are concerned with the sometimes costly and lengthy process of a license amendment that might be required by some types of control room modernization (Joe et al., 2012). Beyond the licensing amendments, there is the potential for added plant downtime for control room replacements. Utilities may be concerned that control room modernization represents a sunken cost that is unlikely to yield significant return on investment. Due to these and other factors, utilities have adopted a piecemeal approach to control room upgrades, only replacing systems as needed (Electrical Power Research Institute [EPRI], 2005). This approach may fail to realize some of the important advantages of newer technologies, since the upgrades may restrict the scope of digital functionality to that needed to achieve only a like-for-like replacement.

The DOE LWRS Instrumentation, Information and Control Systems (II\&C) Research and Development (R\&D) pathway conducts research that is relevant to many aspects of plant modernization using digital technologies, including control room modernization. The DOE LWRS Control Room Modernization project is investigating issues especially relevant to achieving long-term analog technology replacement with enhanced digital technologies. This research targets replacement of aging instrumentation and control (I\&C) technologies with those that build capabilities that are needed in order for nuclear facilities to meet needed safety goals while achieving improved cost performance as delivered through greater efficiencies of a new digital technology base. The goal is to ensure that control room modernization can be carried out in a standardized, cost-effective manner and achieves a meaningful improvement in performance through its implementation. For example, a digital control system (DCS) replacement for a legacy turbine control system might feature digital equivalents of the existing I\&C. It might also go beyond this to include additional features designed to enhance operator control and awareness such as:

- Access important trend information to allow the operators better to understand emerging conditions,

- Perform calculations that must otherwise be done manually by operators,

- Provide prioritized alarm lists that help the operators respond more quickly to transients, 
- Provide helpful checklists to augment paper-based control room procedures, and

- Automate previously manually performed actions.

The goals of the LWRS II\&C R\&D pathway include developing methods and processes through research efforts with candidate advanced digital technologies and their implementation to provide the needed know-how to reliably support their successful introduction in operating plants. This involves both research and development of candidate technologies as well as evaluating their effects on human performance in the control room and other environments of use. Actual plant and replica facilities are needed to carry out realistic research with plant staff to permit valid assessments of these technologies and to study their use under appropriately controlled conditions. Without a rigorous program to establish goals for and study potential performance improvements of control room modernization, utilities may be hesitant to adopt new technologies. The DOE LWRS program aims to provide systematic evaluations of such technologies prior to their implementation in plant main control rooms.

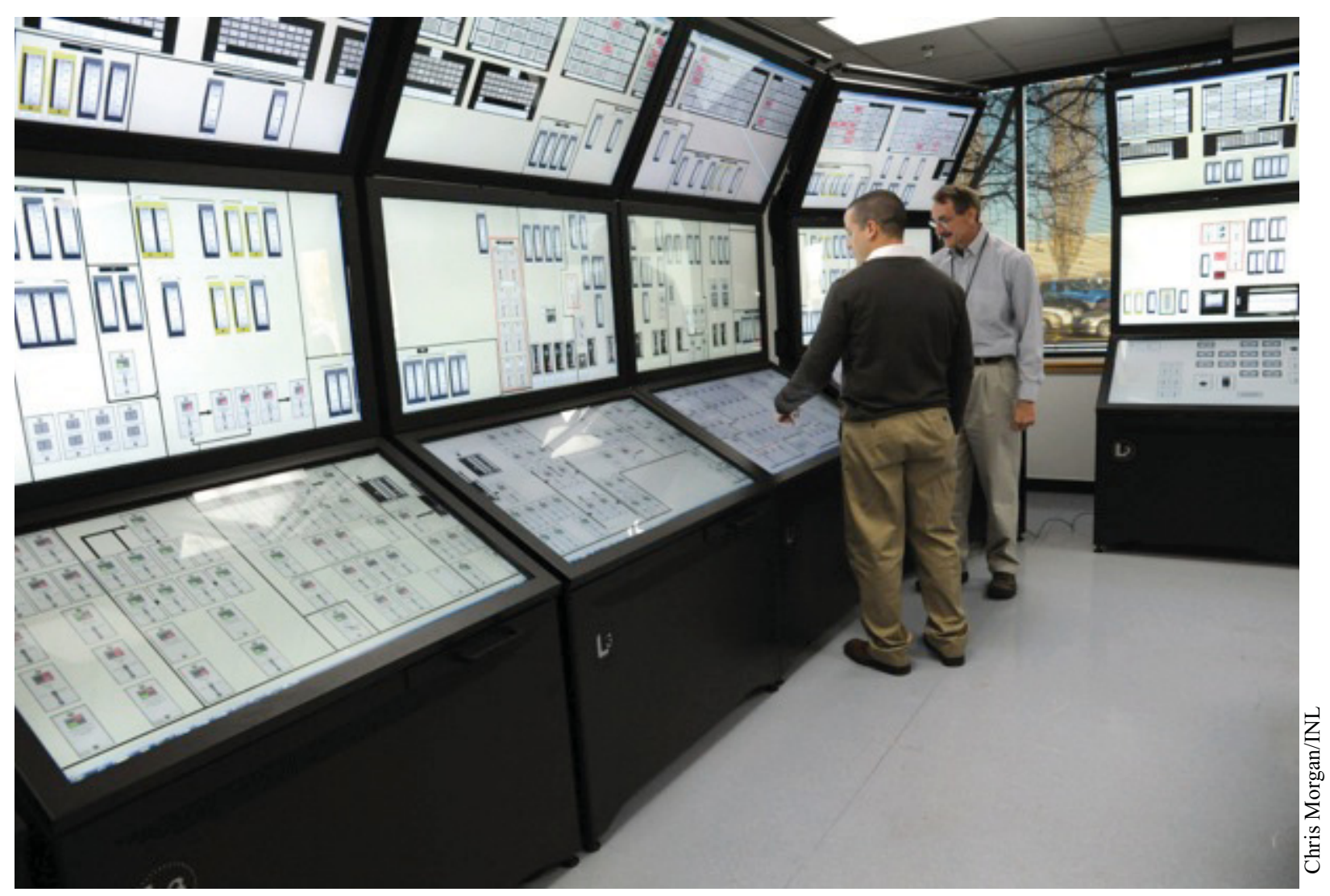

Figure 1. Reactor Operators Using the Glasstop Simulator in the HSSL.

\subsection{Human System Simulation Laboratory}

In order to develop, refine, and evaluate new candidate digital technologies for control room applications, the DOE LWRS program has completed development of a full-scope, full-scale control room simulator at the Human System Simulation Laboratory (HSSL; see Figure 1). The INL report entitled Human System 
Simulation Laboratory, INL/MIS-12-25017 (2012) provides a more comprehensive description of this facility and its many uses. In this report, we talk about the HSSL in the context of the laboratory that contains the simulator. The HSSL also houses other capabilities, such as the Outage Control Center. A full-scope simulator is one that encompasses all functions found in the physical plant. A full-scope simulator might be a tabletop simulator running on a desktop personal computer, provided it has a complete plant model underlying it. In contrast, a full-scale control room simulator is one that mimics the physical layout of the plant's control room. Full-scale simulators are most commonly found in the training simulators found at commercially licensed NPPs. Full-scale simulators are rare for research purposes and are used primarily by vendors in support of the design of new plants.

The HSSL full-scale simulator is based on glasstop simulator hardware. Glasstop simulators represent a virtual display of the control boards found in conventional power plants. Current glasstop simulators follow a convention established by the simulator vendor, GSE Systems, Inc., with their first Virtual Panel (VPanel ${ }^{\mathrm{TM}}$ ) simulator panels: a rack-mounted system comprised of three large LCD displays coupled with touchscreen overlays. The three displays are configured with a horizontally inclined benchboard display, a vertical middle display, and a slanted upper display — which closely conform to the shape of panels in many main control rooms that are designed for operation by licensed personnel while standing. The bottom two displays feature a touchscreen overlay, while the top display is ergonomically beyond the reach of many operators and is thus used for information and instrumentation displays, not for controls. The LCD displays allow the display of analog instrumentation and controls, while the touchscreen overlays allow virtual operation of the controls. The panels are driven by a full-scope simulator model running on a computer within the panel or linked via network to a server running the full-scope plant model that resides elsewhere. An individual panel will only display a portion of the control boards at a time, and operators may navigate to different control boards using the simulator's graphical user interface software. Panels may also be paired together to link a physically larger section of the control boards on the glasstop panels or, with enough panels, the entire main control room. Linked panels work through a simulator server that synchronizes plant parameters across the physical displays.

There are currently three vendors that provide glasstop simulators for NPPs:

- $\quad$ VPanel ${ }^{\mathrm{TM}}$ by GSE Systems, Inc.,

- $\quad$ Orchid® Touch Interface (TI) bays by L-3 MAPPS, and

- $3 \mathrm{KEYTOUCH}{ }^{\mathrm{TM}}$ simulator by Western Services Corporation (WSC).

The HSSL glasstop simulator consists of 15 panels manufactured by L-3 MAPPS. The 15 panels are designed to be a full-scale representation of the front panels of a main control. To represent each control board of a main control room, several glasstop bays are required. Because the control boards at an actual plant may be taller than the Orchid ${ }^{\circledR}$ TI bays, the boards can display the main control room boards of a physical control room at a fixed, scaled size of its actual size by default. In this way, the display may be optimized graphically to ensure readability while maintaining the look of the actual control boards. In such cases, font sizes may need to be enlarged slightly on the displays, while other dimensions of the graphics rendering are kept proportionately sized to the actual control board objects. The glasstop software provided by all three vendors allows magnification of the display if required by the operator, e.g., for reading of finely detailed indicators. More details about the layout considerations for the simulator are described in Chapter 2. As noted, the HSSL simulator is not only full-scale but also fullscope. Full-scale is an artifact of the hardware, while full-scope is a function of the simulator software.

An important component of the simulator is that it's reconfigurable. In other words, it is possible for the same hardware to run different simulator models, in effect physically simulating different plants. While the hardware in use is manufactured as part of an L-3 MAPPS simulator configuration, the LWRS program has installed two different simulators under the same hardware. This reconfigurability will be 
discussed in Chapter 3. Essentially, it requires running different server-client configurations on the same hardware, allowing the simulator manager to switch between virtual machines. At present, the following plant simulator models are installed and operational on the simulator:

- SONGS Unit 2 running under the L-3 MAPPS Orchid® simulator platform,

- Harris Nuclear Plant running under GSE Systems JADE ${ }^{\mathrm{TM}}$ simulator platform, and

- Generic Pressurized Water Reactor (gPWR) running under GSE Systems JADETM simulator platform.

It is anticipated that within the next half year, additional plant models will be added running under the L-3 MAPPS' Orchid® platform and under Western Services Corporation's 3KEYMASTER ${ }^{\mathrm{TM}}$ platform.

The HSSL is also being used to study different concepts of operation for non-control room types of research, such as for advanced outage control. In future stages of research, this facility will be used to investigate the integration of other advanced technologies for decision making in main control rooms and other control centers. This includes computer-based procedures, online monitoring systems, advanced alarm systems, and other types of operator support systems.

\subsection{Unique Characteristics of the LWRS Simulator}

There are three unique aspects of the LWRS simulator:

- Emphasis on current control rooms;

- The full-scale glasstop simulator configuration; and

- Its reconfigurability, allowing for ease in simulation of different plants.

\subsubsection{Emphasis on Current Control Rooms}

The LWRS simulator is designed specifically to support the modernization of control rooms in existing plants. Several other simulator facilities exist to do research on advanced control rooms, most notably the Organization for Economic Cooperation and Development's (OECD) Halden Reactor Project, part of the Institute for Energy Technology in Norway; and the Center for Advanced Energy Research (CAER), part of the University of Virginia. The Halden Reactor Project has for more than 25 years developed and tested advanced human-system interfaces (HSIs) for control rooms (Skjerve and Bye, 2011), with a particular emphasis on new control room designs. Halden's advanced control room concepts tend to be quite different than the control boards found in current plants. Their advanced HSIs tend to be display driven at local operator workstations, with backboards (i.e., physically large display screens behind operator workstations) used primarily as overview displays of plant equipment and status, not for controls. They also differ from the hybrid analog-digital control room solutions, which are the most likely expected near term (i.e., 10 year) product of control room modernization efforts in the U.S. Halden's research on next-generation control rooms and technologies has not targeted existing control room modernization topics to a similar degree as the LWRS program. Although only recently established, the Center for Advanced Energy Research at the University of Virginia (CAER) has adopted a similar approach. It serves as a domestic U.S. counterpart to the types of advanced control room design and research as carried out at the Halden Reactor Project.

The HSSL simulator configuration is based on current control room physical configurations used in the U.S. nuclear power industry. At nuclear power stations today, many of the physical control activities are performed by licensed reactor operators or senior reactor operators while standing at control boards and 
manually manipulating analog types of controls. The glasstop simulator can physically mimic this same configuration, permitting research to be carried out that includes comparison of new physical methods of performing reactor operations with configurations in use today. This allows for researchers to study the effects of systematic changes to the main control room through technology replacement with modern digital I\&C systems. This is viewed by utilities as a needed source of information to permit decisions about the eventual approaches they may adopt as part of plans to modernize main control rooms. It will also permit insights to be drawn about the relative merits of conducting control room modernization following a gradual transition to a hybrid analog and digital $\mathrm{I} \& \mathrm{C}$, or whether other approaches should be considered (e.g., large-scale modernization). The HSSL simulator uniquely supports research into a variety of issues that may need to be considered as a part of such a transition. The types of research between DOE LWRS and Halden Reactor Project and CAER can be seen as complementary: the HSSL simulator is explicitly designed to research control room upgrades involving a phased upgrade from analog to digital $\mathrm{I} \& \mathrm{C}$, whereas the other research simulators are oriented at designing fully digital new control rooms.

Another category of research simulator exists, which is designed for operator performance studies. For example, the U.S. Nuclear Regulatory Commission (NRC) maintains a research simulator at its Office of Research, with a parallel installation at the University of Central Florida (UCF). The objective of this simulator facility is primarily to test the effects of new interfaces on operator performance. Whereas Halden Reactor Project and CAER have a research focus on designing and validating new HSIs, the NRC and UCF simulator focuses primarily on evaluating operator performance in the face of new HSIs-not on creating that new technology. A similar simulator is being configured at the Ohio State University (OSU), with a dual purpose of training Nuclear Engineering students on operations and conducting research on human reliability analysis (HRA). HRA is the study of the causes and the likelihoods of human errors. In support of HRA, the OSU simulator carries a similar function to the simulator at the NRC and UCF. The HSSL simulator facility is capable of such research but is currently using human performance metrics primarily to validate design concepts for control room modernization.

\subsubsection{Full-Scale Glasstop Simulator Configuration}

The HSSL simulator is uniquely configured to mimic a full-scale main control room at an NPP using a glasstop simulator. The three main vendors of glasstop simulators-GSE Systems, L-3 MAPPS, and WSC, as noted in Section 1.3-have created this capability for use at NPPs. In most cases, the intended use of a glasstop simulator provided by the vendor is as a classroom simulator, which may be used for training operators outside the actual main control room simulator. The availability of the main control room simulator is often quite limited (Institute of Nuclear Power Operators, 1992), and the glasstop panel allows access to the full-scope simulator for training without the need to build a second full-scale simulator facility. Initial installations have tended to feature a single panel installation. For example, the three reactors at Palo Verde Nuclear Generating Station currently possess 19 glasstop panels manufactured by WSC, although these panels are not located in a single location and are not linked to represent a single control room. Recent glasstop simulator installations have also included more panels in order to encompass a greater portion of the simulated main control room. For example, the International Atomic Energy Agency (IAEA) recently purchased a six-panel glasstop simulator for use in training. Additionally, as plants have gradually purchased more glasstop panels, it has become desirable to link these panels together to represent more of the control room. For example, SONGS recently added several new panels to their initial three glasstop panels in the classroom, and these have been linked for displaying more of the control boards in classroom exercises. 


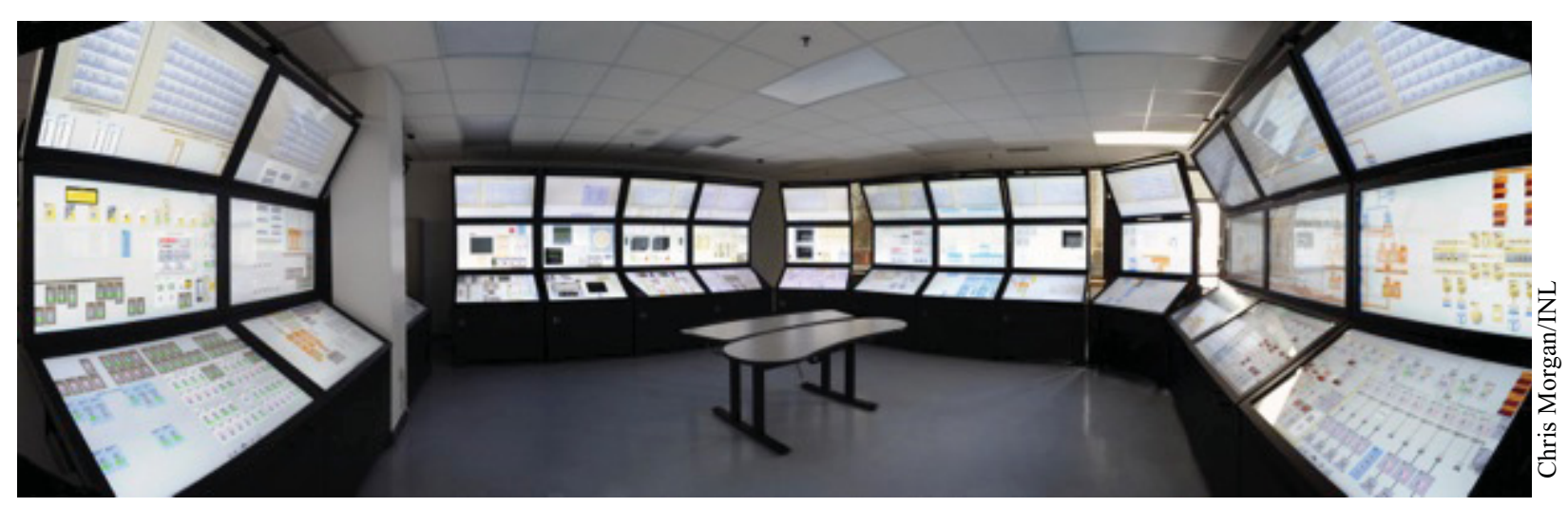

Figure 2. The Full-Scale Layout of the HSSL Glasstop Simulator.

The glasstop simulator features 15 panels linked together to form a single, continuous control room (see Figure 2). To the authors' knowledge, this is the largest single installation of glasstop panels in the world. This layout allows comprehensive integrated system validation studies of control room modernization. Integrated system validation (ISV) is a well-established concept in the nuclear industry (O'Hara et al., 2012). Prior to full-scale deployment of technologies such as control room upgrades, it is essential to test the performance of the system and the human operators' use of the system in a realistic setting. With the advent of a full-scale glasstop simulator, upgraded systems can be integrated into a realistic representation of the actual system and validated against defined performance criteria. This is possible prior to physical deployment at the plant simulator, which requires extensive hardware modification. The ability to test upgrades virtually represents a potential cost and time savings over similar efforts at the actual plant. These savings can ultimately be translated into an improved HSI at the main control room.

\subsubsection{Configurability Between Multiple Plants}

One of the challenges of human factors research findings involving nuclear power has been the issue of the generalizability of the results. The question remains to what extent the findings from one crew generalize to another crew; one control room, to another control room; or one nuclear steam supply system, to another. Each crew, control room, and reactor has unique elements. Yet, there are strong commonalities. The key to successful general guidance for control room modernization is being able to extract the results obtained from research across a wide swatch of the U.S. commercial nuclear fleet. Effectively the best way to ensure the generalizability of LWRS findings is to ensure that multiple crews, control rooms, and reactors are encompassed in the research.

As noted, the control room simulator at the HSSL offers the ability to change plant configurations virtually. Because the glasstop simulator can display the virtual control room panels from different plants by switching the underlying simulator software, it is possible to verify results across different plants. One such effort currently underway involves performing a standardized DCS upgrade across Progress Energy (now Duke Energy Progress) NPPs. An initial study on the use of the systems was performed using the simulator for the Shearon Harris Nuclear Plant, and follow-on studies involving the remaining fleet of plants - specifically Brunswick Nuclear Plant and H.B. Robinson Nuclear Generating Station-are planned within the calendar year. An HSI style guide for the DCS upgrades is being developed based on operator performance for crews from each plant using the LWRS glasstop simulator. The same hardware is being used for each study, but the simulator is customized to accord with the operators' home plants. The HSI style guide is able to incorporate aspects of the crew interactions with the HSI for each plant, 
thus creating a truly overarching and generalizable DCS style guide. By using multiple data points, the findings can be verified and confidently generalized across more of the U.S. commercial nuclear fleet. No other research simulator allows this degree of realistic configurability and versatility.

\subsection{HSSL Simulator Uses}

As previously noted, the simulator is being used for research to support control room modernization at existing power reactors. In the near term, this will take the form of embedding DCS controls on the main panels, whereby the glasstop simulator allows prototyping and testing of DCS configurations, for example. The purpose of the LWRS simulator for such studies is to facilitate prototyping and testing of upgrades in a manner that can be generalized to a wide range of reactors in the U.S. Since no main control room HSI modernization effort has been completed in the U.S. to date, the LWRS Control Room Modernization project is teaming with partner utilities to conduct research on technologies and the process of upgrading the main control room. While the upgrade will be completed by the utilities and their contractors and vendors and not by DOE parties, it is important that the process is openly documented in order to prevent proprietary and one-of-a-kind processes that must be learned anew by each utility. As such, the LWRS Control Room Modernization project is assisting the process and making the steps of the process public domain for use by utilities. Existing guidance by the U.S. NRC (e.g., NUREG-0700 and NUREG-0711) and by the Electrical Power Research Institute (e.g., 2005) provide comprehensive information on successful control room upgrades. These documents, however, fall short of offering the step-by-step guidance for conducting the control room upgrades that is so needed by industry. Forthcoming DOE reports on control room modernization are anticipated to provide an important link in guidance between the U.S. NRC and industry guidelines.

One of the identified shortcomings in completing control room modernization is a lack of control room human factors expertise at the plants (Joe et al., 2012). Such expertise is needed for successful control room upgrades. The following characteristics show the value of human factors for control room modernization efforts:

- Understanding of human skills and limitations and how these apply in the interface with digital technologies.

- Ability to define human-centered design guidance for HSIs based on best usability practices.

- Understanding of applicable human factors standards (e.g., NUREG-0700) and how to apply them in the design of HSIs.

- Understanding of when it is appropriate to deviate from human factors standards and ability to defend and justify any such deviations.

- Ability to apply systematic operator-in-the-loop evaluation approaches to validate HSI designs.

TheLWRS program is conducting research into critical issues of analog control room modernization together with participating utilities and is documenting knowledge gaps that need to be addressed in the future.

Chapter 4 provides an example of how the glasstop simulator has been used and will be used as part of a systematic control room modernization effort. The simulator provides the platform for prototyping DCS designs and evaluating them using well-established human factors methods.

\subsection{Summary}


Table 1 below provides a comparison of the different characteristics and applications of research simulators discussed in this chapter. The comparison is not meant to be exhaustive, and there may be other characteristics of research simulators or, indeed, other research simulators that aren't covered in this list. The HSSL provides a unique, complementary set of features that are not currently mirrored in simulators at plants or at vendors. These features ensure that the simulator both supports current industry needs and serves the need for fundamental research. Initial efforts using the simulator are designed to provide a testbed for modernization and to walk through the upgrade process in utility control rooms. The near-term strategy for the LWRS Control Room Modernization project is threefold:

- Identification of a streamlined human factors approach for supporting control room upgrades.

- Identification of any research gaps that are not currently being addressed by industry.

- Identification of technologies that would assist industry in achieving greater operator performance, reliability, or safety in the control room.

Table 1. Control Room Research Simulator Characteristics (as of February 2013).

\begin{tabular}{|c|c|c|c|c|c|c|c|}
\hline & & Halden & CAER & NRC & UCF & OSU & HSSL \\
\hline \multirow{5}{*}{$\begin{array}{l}\text { General } \\
\text { Characteristics }\end{array}$} & Full-Scope & $\checkmark$ & $\checkmark$ & $\checkmark$ & $\checkmark$ & $\checkmark$ & $\checkmark$ \\
\hline & Workstation & $\checkmark$ & $\checkmark$ & $\sqrt{ }$ & $\sqrt{ }$ & $\sqrt{ }$ & $\sqrt{ }$ \\
\hline & Panels & & & & & & $\sqrt{ }$ \\
\hline & Full-Scale & & & & & & $\checkmark$ \\
\hline & Reconfigurable & $\checkmark$ & $\checkmark$ & & & & $\checkmark$ \\
\hline \multirow[t]{5}{*}{$\begin{array}{l}\text { Plant } \\
\text { Characteristics }\end{array}$} & $\begin{array}{l}\text { Plant-Specific } \\
\text { PWR }\end{array}$ & $\checkmark$ & $\checkmark$ & & & & $\checkmark$ \\
\hline & $\begin{array}{l}\text { Plant-Specific } \\
\text { BWR }\end{array}$ & $\checkmark$ & & & & & $*$ \\
\hline & $\begin{array}{l}\text { Non-Plant } \\
\text { Specific PWR }\end{array}$ & & $\sqrt{ }$ & $\sqrt{ }$ & $\sqrt{ }$ & $\sqrt{ }$ & $\sqrt{ }$ \\
\hline & Existing Plant & $\checkmark$ & & & & & $\checkmark$ \\
\hline & New Build & $\checkmark$ & $\checkmark$ & & & & $*$ \\
\hline \multirow[t]{3}{*}{ Applications } & Training & & & $\checkmark$ & & $\checkmark$ & $*$ \\
\hline & HSI Design & $\checkmark$ & $\checkmark$ & & & & $\checkmark$ \\
\hline & $\begin{array}{l}\text { Operator } \\
\text { Evaluation }\end{array}$ & $\checkmark$ & & $\checkmark$ & & $\checkmark$ & $\checkmark$ \\
\hline
\end{tabular}

*Represents available but not currently scoped functionality under the DOE LWRS Program.

Preliminary efforts are primarily addressing the first need — creating a streamlined human factors approach that may be used across the industry. However, the HSSL simulator directly supports all three efforts by being the enabling platform for prototyping, validating, and researching new HSIs for the control room.

The Long-Term Instrumentation, Information, and Control Systems (II\&C) Modernization Future Vision and Strategy report (Thomas and Hallbert, 2013) outlines future uses for the HSSL simulator. The purpose of the simulator is not simply to build a unique capability needed to address research needs. The II\&C R\&D pathway conducts research to create capabilities in six enabling areas as shown in Figure 3. The current efforts described in this report to build a configurable simulator support all of these enabling areas, though many of the examples shown here are are applicable to Pilot Project 1.1, Incorporating 
Digital Upgrades in an Analog Control Room. Examples of the intersection between the simulator and other pilot projects are described below:

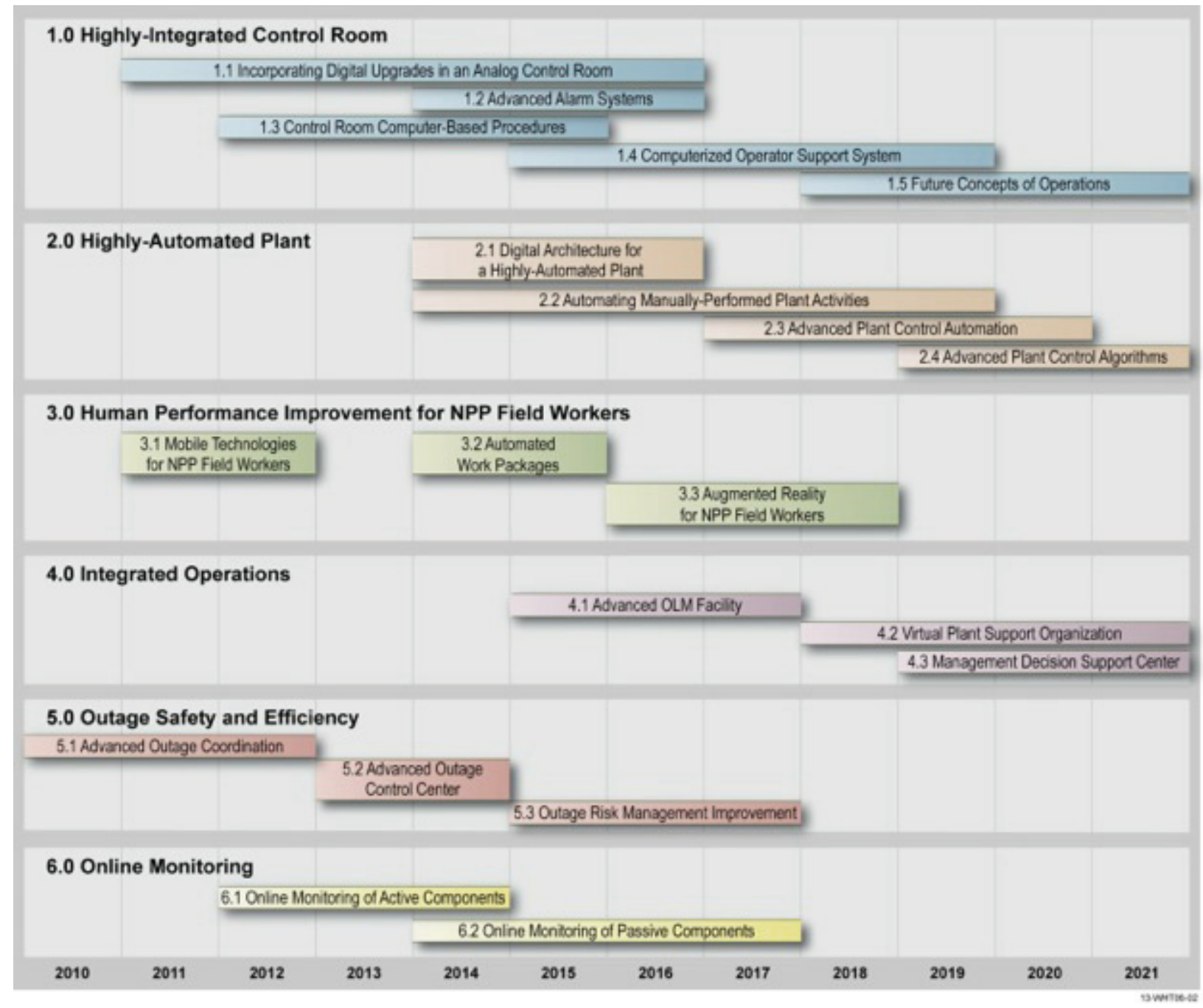

Figure 3. Summary of the Pilot Projects for the LWRS II\&C Systems Technologies R\&D Pathway (from Thomas and Hallbert, 2013).

- 1.0 Highly-Integrated Control Room: As noted, the simulator buildout was initiated as part of the project on Control Room Modernization (which falls under Pilot Project 1.1). The same control room simulator facility becomes the basis of research and development efforts in advanced alarm systems (Pilot Project 1.2), which are a subsystem of the overall control room modernization. Likewise, computer-based procedures (Pilot Project 1.3), when implemented in a control room, will require the simulator as a development test bed, with procedures embedded in the DCS. Operator support systems (Pilot Project 1.4) will provide advanced visualizations that support operators' situation awareness. Such support systems may, for example, represent advanced neutronics displays not currently available to operators but that are now possible through advanced computer models. These computer models may tie into updated plant computers already being implemented as part of current control room modernization efforts. Finally, future concepts of operation (Pilot Project 1.5) will 
investigate opportunities to increase operator efficiencies and flexibility in the control room. Again, the focus is on technologies that will meaningfully augment current control rooms and for which the HSSL simulator is intended to serve as the test bed.

- 2.0 Highly Automated Plant: This project has not yet begun, but the simulator serves as the platform to develop and validate automation technologies for the control room. Most near-term control room upgrades supported under Area 1.0 include primarily display automation - the incorporation of additional sensor and status information that must currently be gathered or calculated manually. Display automation ports frequently used and necessary information to a DCS that can be easily accessed by operators. Such display automation avoids the operator ping-pong effect of going between different panels to gather relevant information and thereby saves considerable time and reduces the potential for error. Beyond display automation is control automation - the control system performs tasks on behalf of the operators. Such automation holds the promise to yield further efficiencies in the control room, yet such functionality must be carefully validated to ensure no adverse effects due to the diminished role of the human operator. Using the simulator for validation studies for control automation can ensure the automation's efficacy under this area.

- 3.0 Human Performance Improvement for NPP Field Workers: Field workers are an integral part of supporting the main control room, but the communication between reactor operators and field workers is largely accomplished via telephone or public announcement systems. One goal of the Area 3.0 series of pilot projects is to find ways to improve communication between the main control room and the field. This may include nonverbal updates to status indications in the control room, allowing operators to better track what is being done in the field. Such augmentations to the HSI are ideally suited for initial proof of concept using the HSSL simulator platform.

- 4.0 Integrated Operations: The central idea of this series of pilot projects is to create centers where plant expertise can be located centrally and shared, thereby omitting the need to maintain a full contingent of subject matter experts at each plant. With the exception of emergency operations centers, there is no plan to create remote control rooms. Yet, some of the expertise required to diagnose or manage scenarios might be handled by backup operators who can be enlisted as support staff to the actual reactor operators. Such an integrated operations center would be especially useful for planning or incident mitigation. The HSSL simulator provides the capability to stage a control room remotely, which may be linked to the actual plant control room or training simulator to mirror indicators in the full control room. Supplemental remote staff might assist the senior reactor operator in monitoring crew activities or plant responses. Such remote control room capabilities do not currently exist in plants, and the HSSL simulator could serve as the proving ground for remote control room functionality. Specific pilot projects plan to look at advanced online monitoring facilities, virtual plant support centers, and management decision support centers, many of which will look to interface with the main control room and may avail themselves of the HSSL simulator.

- 5.0 Outage Safety and Efficiency: These pilot projects culminate in research on outage control centers, which coordinate activities surrounding plant maintenance and refueling during outages. An outage control center will be collocated at the HSSL, adjacent to the control room simulator. As with the field workers described in Area 3.0 above, a key component of outage management is effectively using field workers. Scheduling activities, many of which occur concurrently and have the potential to take critical systems offline during maintenance activities, must be carefully planned and coordinated as part of outage management. This series of pilot projects is looking at ways to improve communication (including, especially, communication between the field and the main control room). Such communication may be achieved in part through the infusion of new technologies that can automate the tracking of information and activities. Such information also needs to be communicated to the main control room, as the availability of equipment must be fully understood by reactor operators, even during low power and shutdown. The types of information that would be useful to control room personnel may be tested using the HSSL simulator in conjunction with a simulated outage control center. Additionally, there is opportunity for technology transfer from the outage 
control center to the main control room, since the outage control center does not have legacy HSIs to constrain its development. As new technologies are adopted for use in the outage control center, their potential integration into the main control room may be tested in the HSSL control room simulator.

- 6.0 Online Monitoring: Currently, there is minimal online monitoring at existing plants, and much of the task of verifying remote system functionality must be accomplished by field workers. For example, for most plants, there is no concise indication that the emergency diesel generators are functioning properly, and an engineer assigned to monitor the operational status of the diesel generators and check on status indications. As additional sensors are made available in each plant for online monitoring, the data can be fed into the main control room DCS. The optimal mechanism for this information presentation, including alarms and trending, has yet to be established. The HSSL simulator will be used to establish conventions for information presentation.

As can be seen, the HSSL simulator is part of a comprehensive research strategy that encompasses both near-term practical goals of control room modernization and long-term goals to support research on overall plant sustainability. 


\section{SIMULATOR LAYOUT}

\subsection{Introduction}

Many possible control room layout configurations were discussed in Boring et al. (2012), ranging from workstation-based solutions to glasstop panels, to developing a digital full-scope mockup of a conventional nuclear control room. Eventually, based on long-term research goals, glasstop panels, as shown in Figure 4 were selected. The lower two displays feature touchscreens to allow operators interaction with virtualized controls. The upper display, which is out of operators' reach, is a nonaugmented LCD screen without touch interaction.

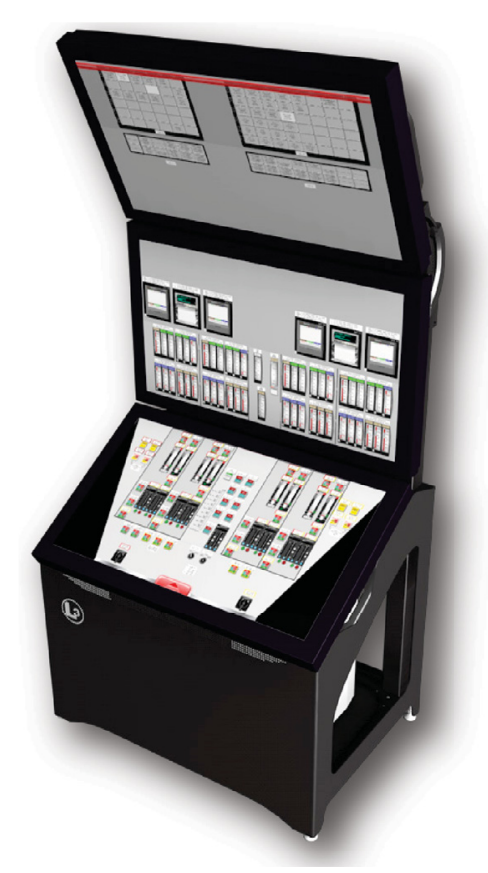

Figure 4. L-3 Orchid® TI Bay.

In this chapter, the following topics are discussed:

- Control room layout considerations, and

- Currently adopted configuration of the panels.

\subsection{Panel Placement}

Issues to consider when designing the panel placement in the control room include:

- Room layout requirements,

- Number of panels,

- Dimensions and design of each panel, and

- Panel layout. 
In addition to the above considerations, the control room should be designed for more than just day-today operations. The layout should consider future upgrade needs and maintainability. For example, maintainability may stipulate that a certain amount of access space be allowed behind the panels to ensure that technicians can service the computers and displays.

\subsubsection{Room Layout Requirements}

There are number of factors that contribute to an optimal room layout requirement. These include:

- Room dimension, i.e., length vs. width and overall room symmetry;

- Light reflection, i.e., the panels should be placed such that the reflection from ceiling lights is minimized;

- Location of windows, i.e., the position of windows and the resultant glare due to light from the windows should be assessed in the placement of the panel to avoid window glare;

- Ventilation system, i.e., the panels must be placed to allow proper heat transfer and cooling;

- Accessibility, i.e., the panels should be placed in accordance with laws on path width, door clearances, and room ingress and egress appropriate for safety and accommodation for mobility impairments.

\subsubsection{Number of Panels}

The required number of panels to replicate a full-scale mockup of a conventional nuclear control room depends on budget, mapping between nuclear control room panels and digital representation on each panel, and the dimensions of each panel.

\subsubsection{Dimensions and Design of Each Panel}

The dimensions of each panel are based on the dimensions of the visual display monitors (e.g., 46-inch display measured diagonally), the horizontal-to-vertical aspect ratio (16:9), and the display resolution (e.g., 1920 horizontal by 1080 vertical pixels). Additionally, the standing height (e.g., the position of the benchboard above the floor) affects the dimensions of the panel, as does the angle of the displays (e.g., the rise of the benchboard display front to back or the forward-lean angle of the top annunciator-dedicated display).

\subsubsection{Panel Layout}

As depicted in Figure 5, the two most common layouts of control rooms are the horseshoe layout (e.g., a semicircular layout built around three walls) or the L-shaped layout (e.g., panels placed against two walls). Most conventional nuclear control rooms in the U.S. are close variants of either of the two layouts. Within these layouts, enough space is maintained in and around the panel so that multiple operators can simultaneously move around the space as required to control the plant. 
(a)

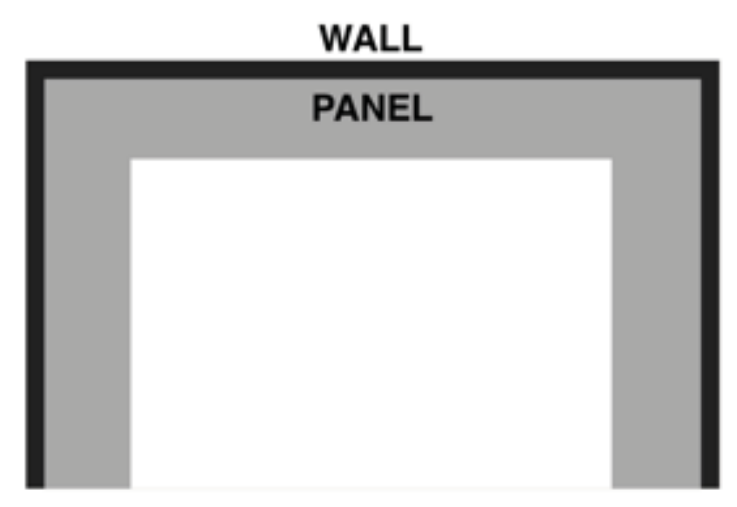

(b)

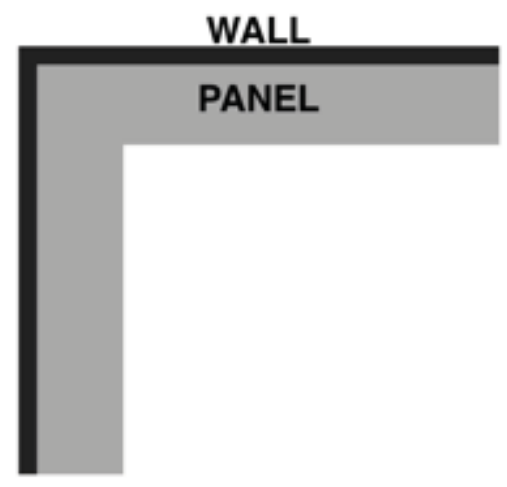

Figure 5. Common Control Room Layouts: (a) Horseshoe and (b) L-Shaped.

\subsection{Control Room Mockup}

The current LWRS full-scale mockup of a conventional NPP control room includes 15 identical glasstop panels manufactured by L-3 MAPPS and depicted in Figure 4. Many different control room layouts were proposed in the initial buildout phase of the control room facility. Two of the proposed layouts are shown in Figure 6. The proposed configuration on the left was based on the room specification at the Center for Advanced Energy Studies (CAES) at INL, the initial location of the HSSL. The CAES lab space allowed a horseshoe layout of the panels. However, because the CAES facility was a shared lab space, it quickly became apparent that the presence of 15 panels would dominate the space. The buildout was therefore shifted from CAES to a dedicated lab facility in the Engineering Research Office Building (EROB) at INL. Based on the EROB room dimensions, the panels needed to be arranged in different manor. As seen on the right on Figure 6, the panels are arranged in a circular fashion to accommodate room dimensions and minimize obstruction by a required support beam in the room. This wraparound layout is a variant of the traditional horseshoe layout.

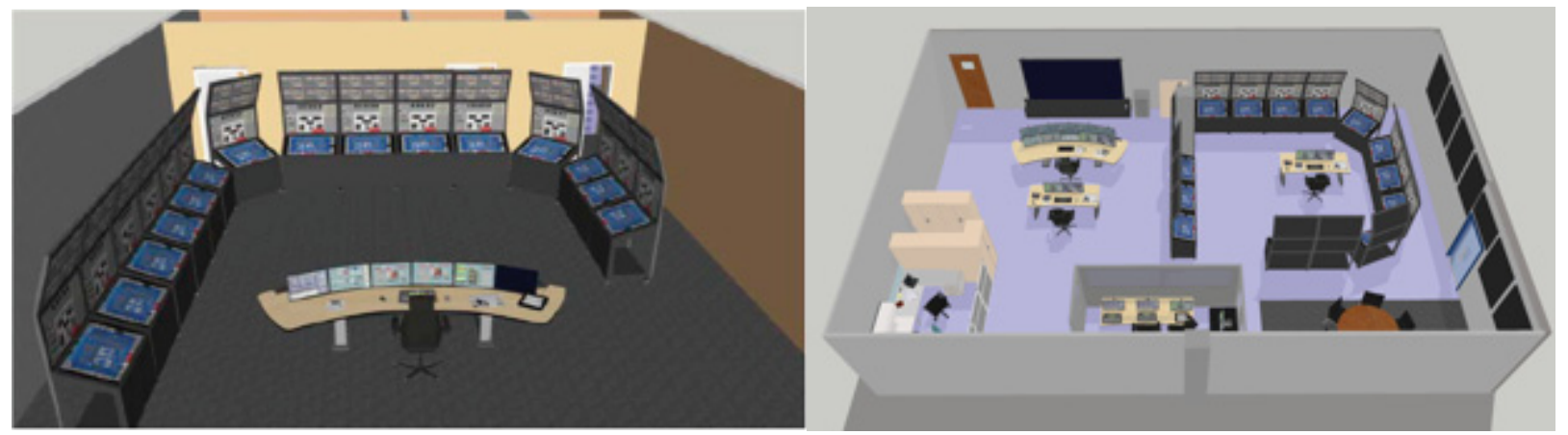

Figure 6. Three-Dimensional Schematic Representations Used in Planning the Layout of the Simulator Buildout.

The observer gallery is an important aspect of the research simulator capability. This observer station is similar to the observation gallery found in most training simulators - an area where the simulator instructor station resides and where bystanders such as operations experts, trainers, and HFE professionals can monitor crew activities unobtrusively during scenario walkthroughs. Note that the semi-enclosed 
layout of the observation station in EROB (see Figure 7) allows observers only partial line-of-sight monitoring of operator activities. This renders the panel layout in Figure 7 non-optimal. To address this issue and to allow more comprehensive data logging, three overhead cameras (see example in Figure 8) are installed around the simulator, allowing observers to remotely monitor operator activity on dedicated computer monitors in the observation center. Additional mobile cameras are positioned around the control room as needed. Example images from mobile cameras can be seen in Figure 9. The observation station can be seen in the background of the topmost image in Figure 9.

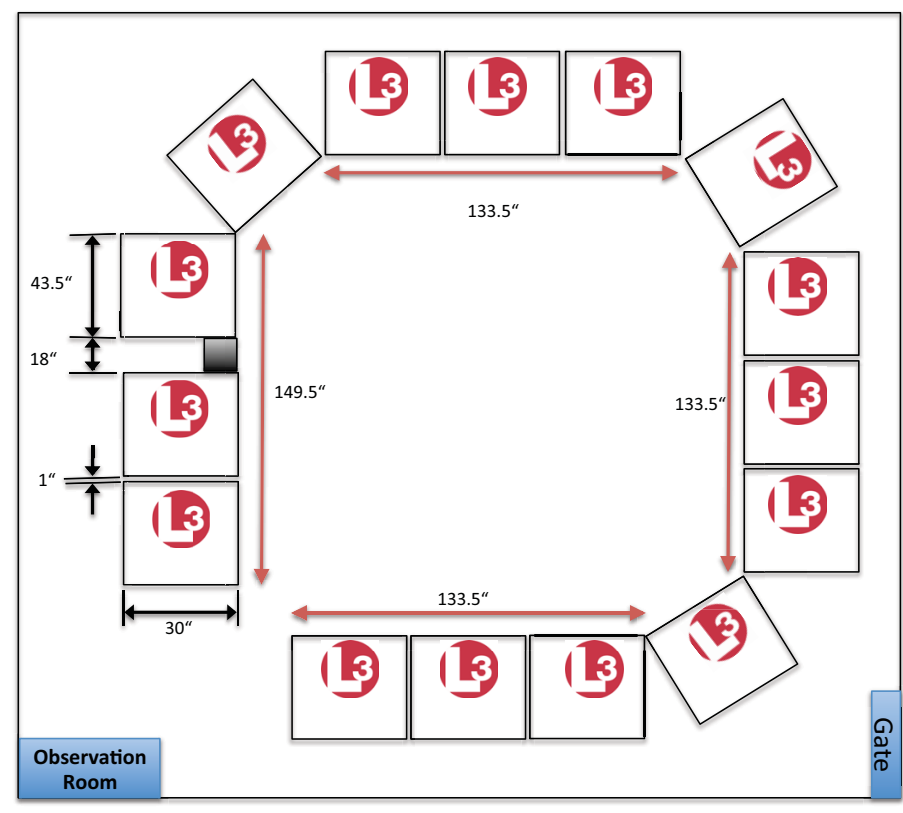

Figure 7. A Schematic Representation of the HSSL Simulator Layout.

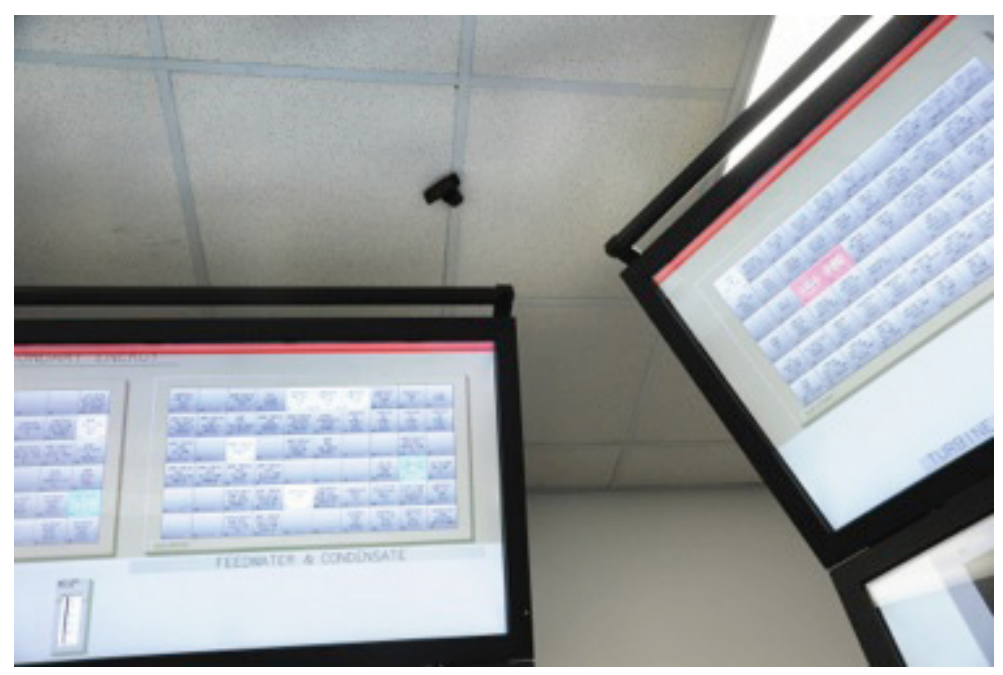

Figure 8. Placement of a Ceiling Camera for Observation. 


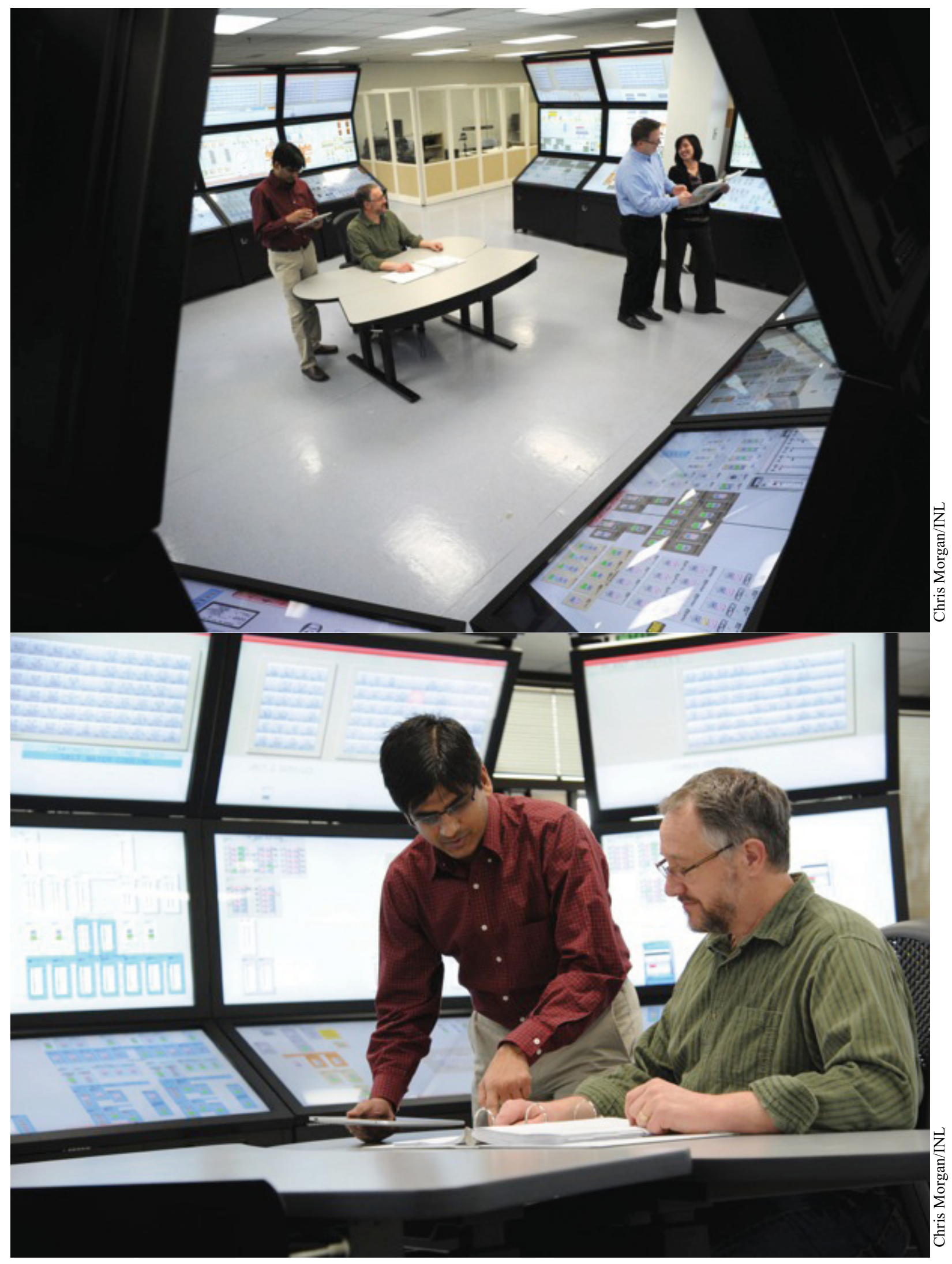

Figure 9. Mobile Camera Views of Staff in the HSSL Simulator. 


\subsection{Configuring the HSSL for different Control Rooms}

The HSSL simulator can be configured to realize different physical control rooms. In this section, we describe the configuration of the HSSL to realize the control rooms for two different nuclear power plants using the installed 15 glasstop panels. . It includes discussions of the L-3 developed San Onofre Nuclear Generating Station (SONGS) simulator and the GSE developed simulator for the Shearon Harris Nuclear Plant.

The mapping of SONGS control systems on the glasstop panels is straightforward, as shown in Figure 10, because both the same vendor developed both the glasstop panels and underlying simulator and plant model. All the control systems on each actual control room panel span over either two or three glasstop panels. Figure 9(a) and Figure 9(b) show the mapping of specific control room panels, numbered according to the engineering designation used at the station. For example, control systems on the control room (CR) panel CR61 are displayed (mapped) across two glasstop panels. Similarly, CR53 and CR56 can each be displayed with two glasstop panels. The control systems on the control room panel CR64 require three glasstop panels, as do CR54 and CR57. Thus, the main front panels of the SONGS simulator - the panels CR57, CR56, CR58, CR53, CR64, and CR61-can be displayed in their entirety using the 15 glasstop panels. This confirms the LWRS simulator is a truly full-scale control room simulator.

(a)

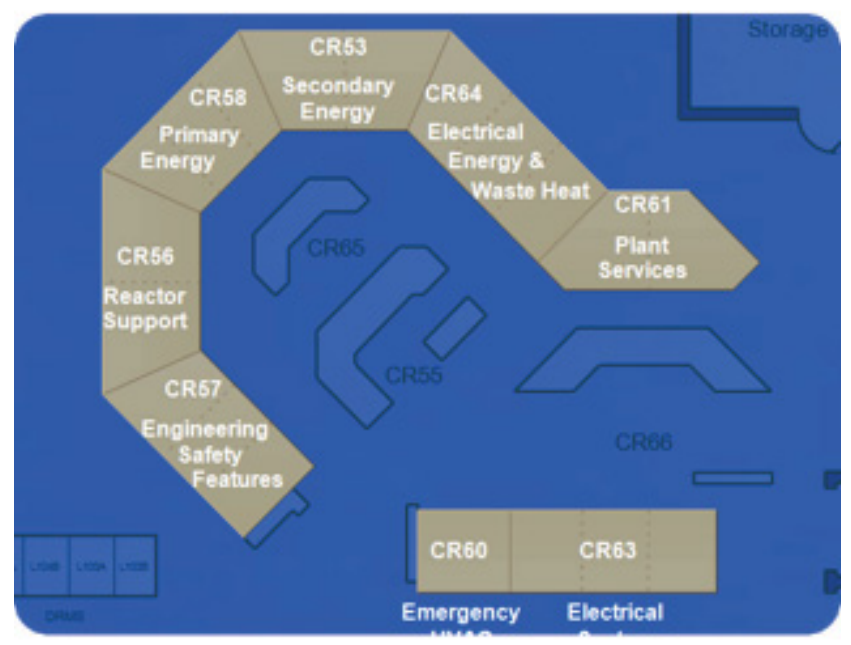

(b)

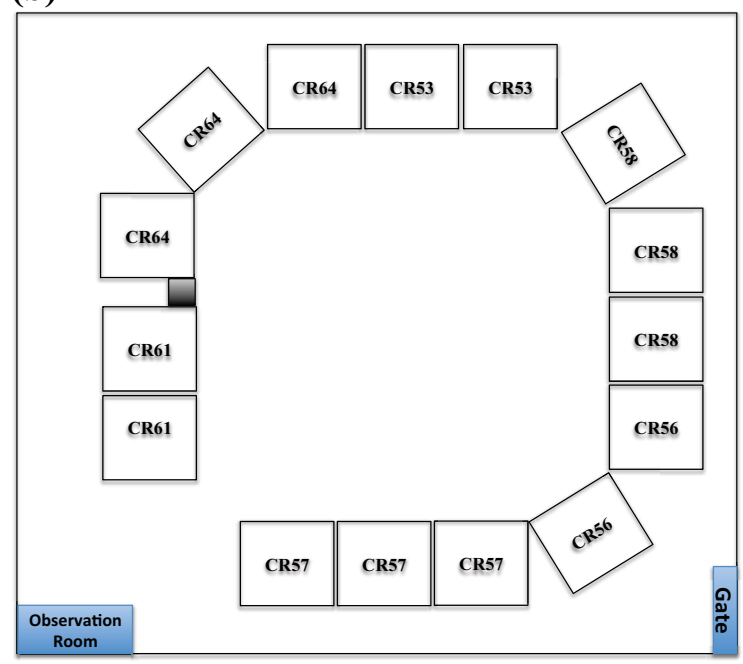

Figure 10. Mapping of (a) Control Boards to (b) the Glasstop Panels on an L-3 Configuration.

Figure 11 shows a composite rendering of panel displays with control systems from the panel CR57. The top photo shows the rendering across nine displays in the software, while the bottom photo shows how these images appear on the glasstop panels. Figure 11 shows the mapping of CR57 on three L-3 panels. Note that the transition of control systems and alarms across two L-3 panels is smooth with no mid-object breaks on each L-3 panel. The graphics have been optimized to ensure specific instruments and controls are not interrupted by the bevel between physical panels. 


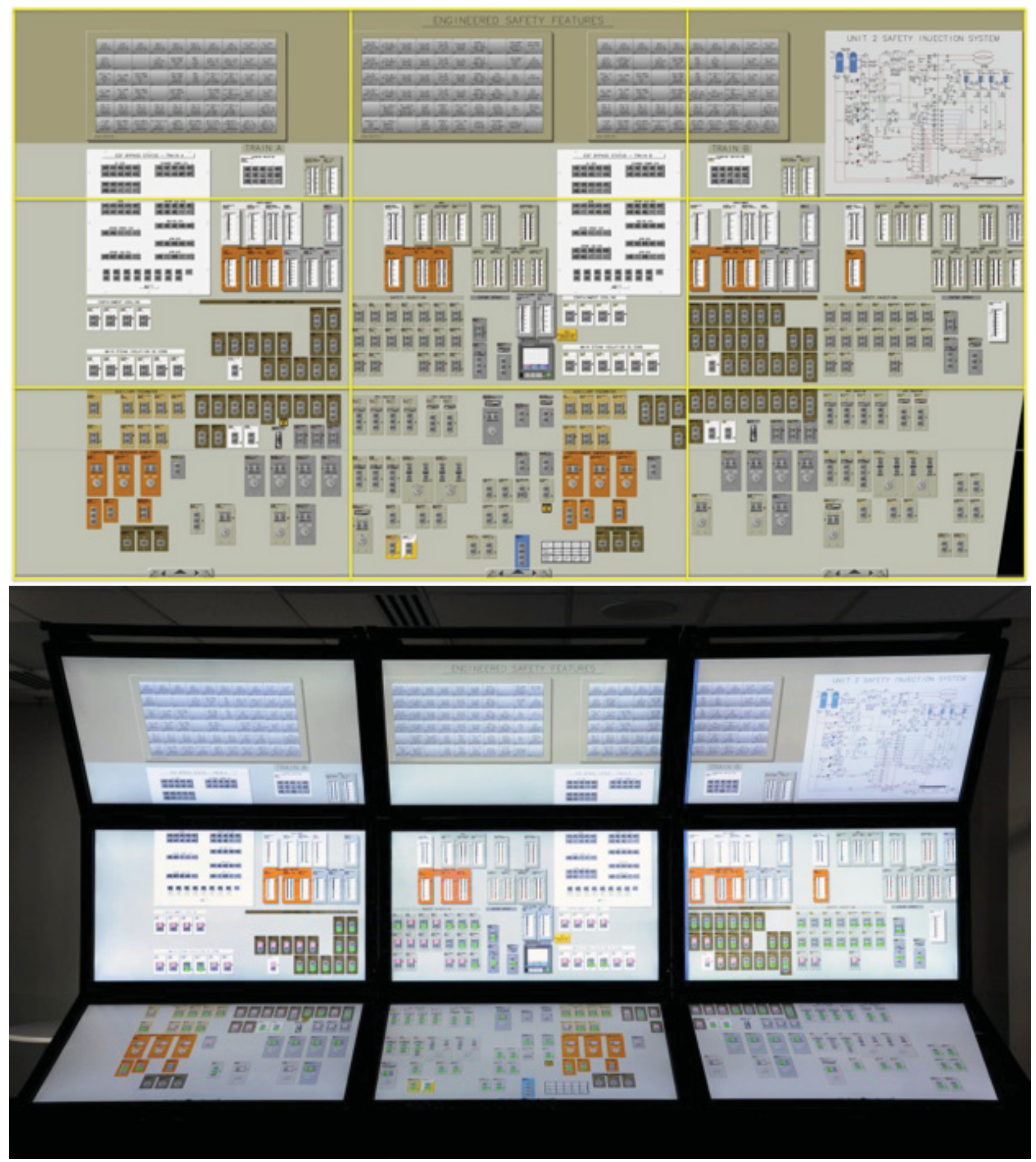

Figure 11. Mapping of the Reactor Support Panel CR57 on Three Glasstop Panels.

Figure 12(a) shows an overview of the Harris Nuclear Plant control room simulator layout developed by GSE. The control systems on the panels for In-core Instrumentation (II) and Nuclear Instrumentation (NI) are on separate stand-alone cabinets respectively. Based on the panel display resolution calculation, it was determined that mapping GSE simulator control systems would require 16 glasstop panels. In order to accommodate the GSE provided plant simulator model on 15 panels, only one of the protection channels 
on the NI panel is displayed at a given time. However, by scrolling, other redundant protection channels on the NI panel can be accessed. Figure 12(b) shows the schematic representation of mapping the GSE provided plant simulator model across 15 glasstop panels. The GSE software does not delineate panels, and the front panels in the control room are represented as a continuous working area. As such, panel boundaries may occur midway through the displays. This lack of hard panel boundaries is represented by the notation II/NI, AA/A1, A1/A2, B1/C1, B2/B1, D1/BB, and D2/D1.

(a)

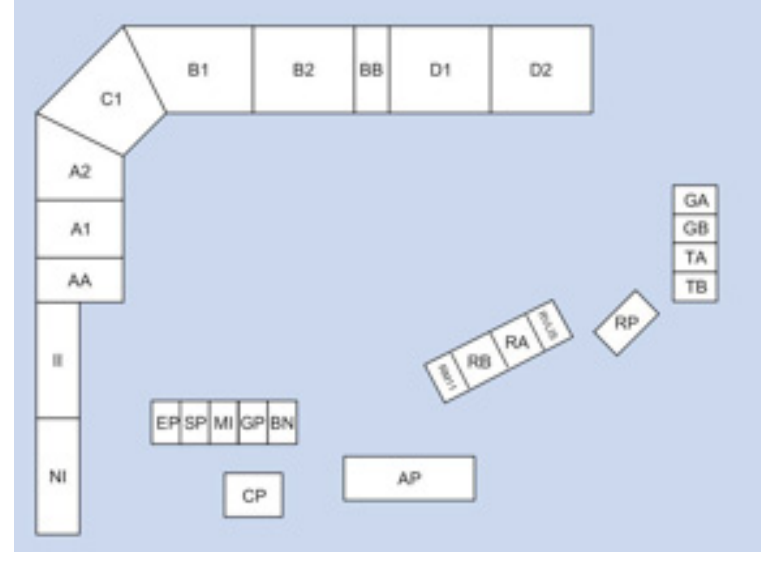

(b)

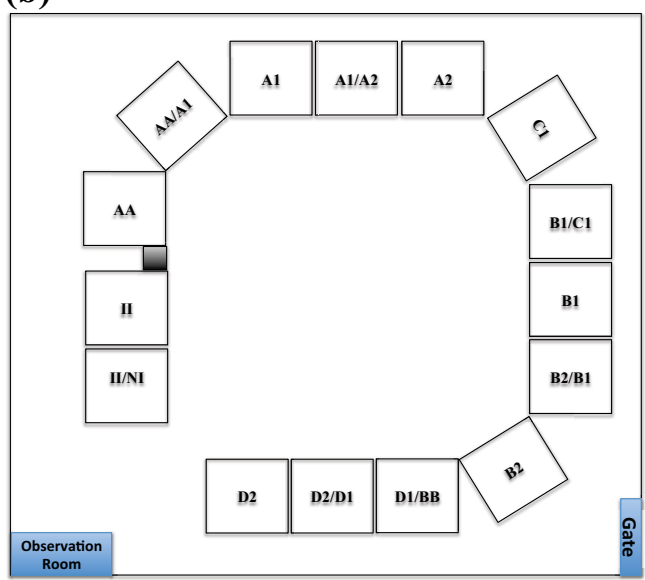

Figure 12. Mapping of (a) Control Boards to (b) the Glasstop Panels on a GSE Configuration.

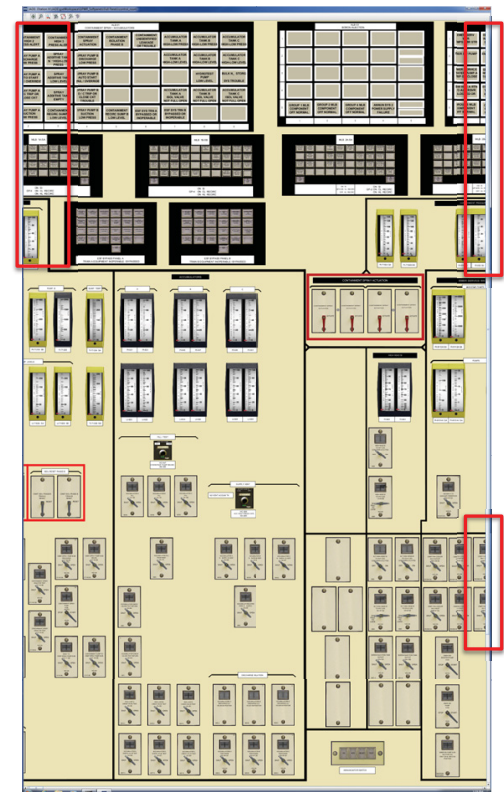

Figure 13. Screenshot of a Panel with Portions of Control Systems and Alarms Not Displayed.

The software for the Harris plant model was originally designed for display on a single glasstop panel. An artifact of this design is that the transition between I\&C objects (e.g., controls or gauges) across panels is not discrete. The seamless panel display on the GSE simulator means that objects may be split across displays. For example, if the control panel D1 is selected for display on a panel (see Figure 13), some of 
the control systems and alarms on the D1 control panel are not displayed completely. Because each

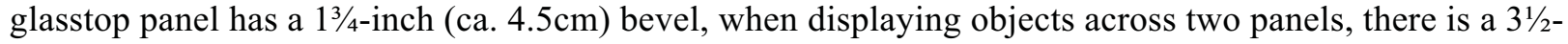
inch $(\mathrm{ca} .9 \mathrm{~cm})$ intersection of the objects between the panels. This can result in the inability to read the instrumentation or activate the control without scrolling the panel display sideways. Alternately, objects may need to be overlapped on the panel displays so entire objects are available on each panel.

Overlapping the displays interrupts the continuity of the panel displays across the control room and increases the number of glasstop panels required to display the plant control boards. ${ }^{1}$

\footnotetext{
${ }^{1}$ L-3 segments each panel discretely to fit across displays. In this process, some objects are shifted up or down or right or left in order that they are never intersected by the display bevel. This, however, results in some deviation between the actual control boards and the glasstop representation. GSE's use of a continuous display results in a more faithful rendition of the parent plant, although this fidelity may be visually compromised by the need to overlap portions of displayed area to compensate for the bevel.
} 


\section{A CONFIGURABLE HARDWARE AND SOFTWARE ARCHITECTURE}

\subsection{Client-Server Architecture}

In general, a client-server software architecture consists of two parts-client systems that interface with the user and server systems that handle back-end processing - both communicating over a computer network or on the same computer. A client computer and a server computer are usually two separate devices, each customized for their designed purpose. In some cases, a given device can function both as a client and a server for the same application. Likewise, a device that is a server for one application can simultaneously act as a client to other servers for different applications.

A client device typically sends a service request or an information access request to the server over the network. A server device typically stores files and databases including more complex applications like Web sites. Server devices often feature higher-powered central processors, more memory, and larger disk drives than clients.

\subsection{L-3 Simulator Platform}

L-3 MAPPS' plant simulator platform uses a client-server software architecture as described in Section 3.1. Figure 14 schematically represents the L-3 MAPPS' client-server network setup. Two of the main components of the L-3 client-server setup include Orchid ${ }^{\circledR}$ Network Loader (NL) and Orchid ${ }^{\circledR}$ Instructor Station (IS). The client-server connection is over a wired Ethernet connection because of the bandwidth requirement (a minimum of $1 \mathrm{~GB}$ of bandwidth is required per the L-3 specification).

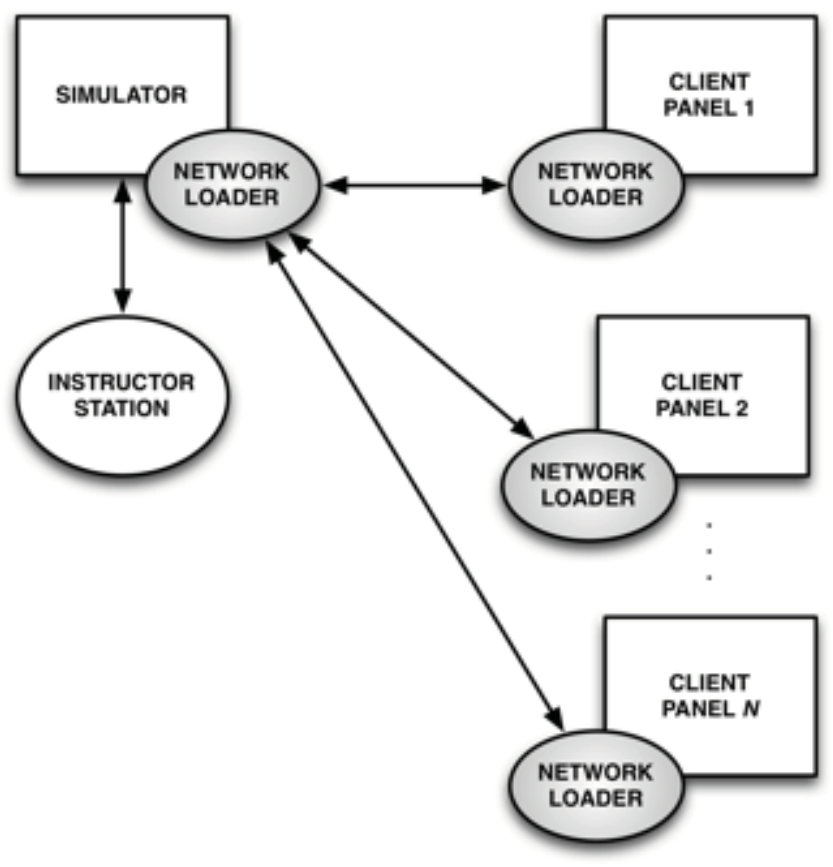

Figure 14. A Schematic Representation of L-3 MAPPS' Client-Server Network Setup. 
Orchid ${ }^{\circledR}$ NL, as shown in Figure 15, is L-3 MAPPS' tool for detecting and controlling simulation software over the network. Orchid $\mathbb{R}$ NL primarily handles the exchange of information between the server and the client, but this server-client framework provides additional functionality, such as the ability to:

- Load and unload the simulation across all clients,

- Monitor the status of simulations on the different clients across the network,

- Identify which machines are online and communicate with those networked machines (e.g., Figure 15 shows a simplified example of a server, sim-inl-01, connected with four clients, SIM01 through SIM0 4), and

- Synchronize information across different computers.

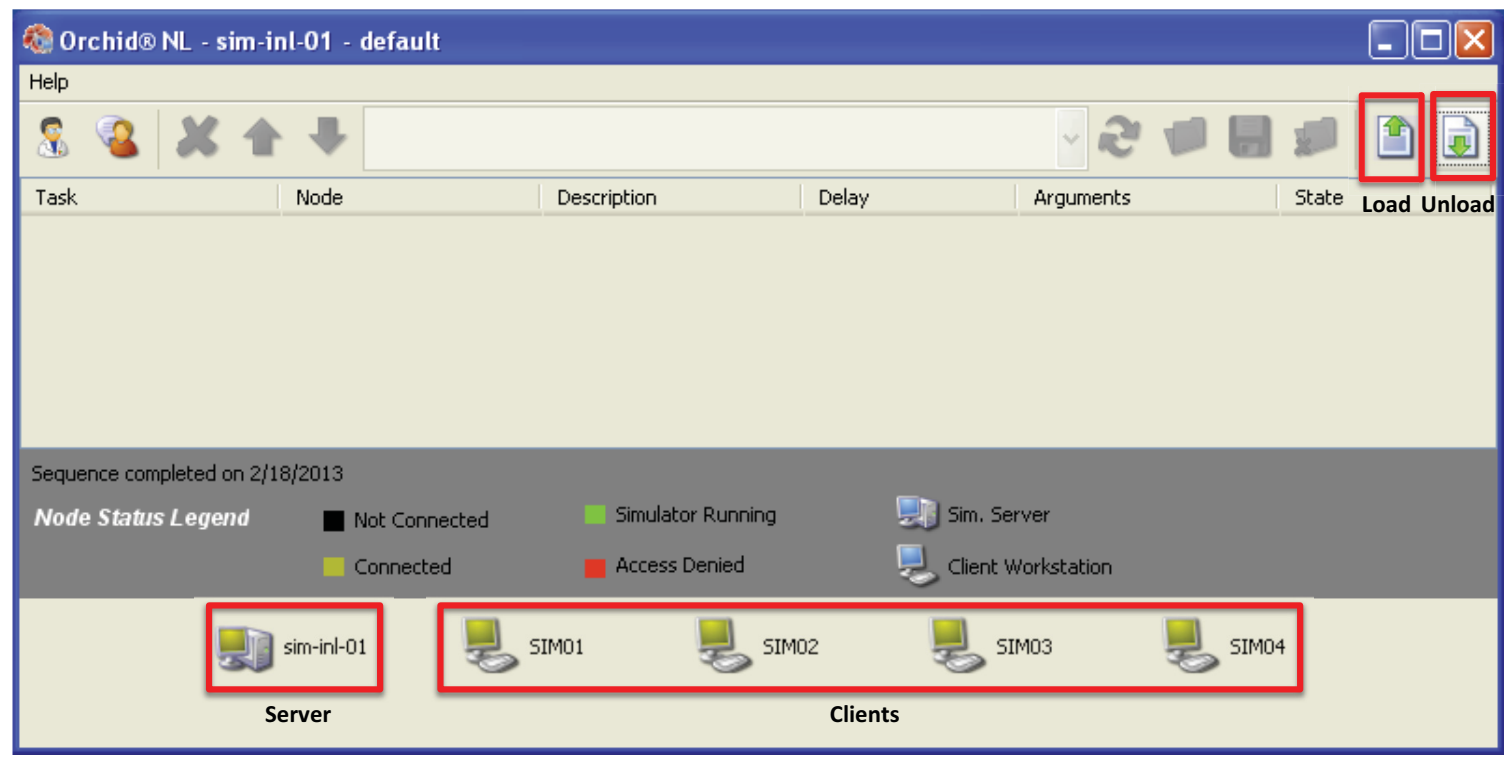

Figure 15. Default Orchid® Network Loader Window.

Orchid ${ }^{\circledR}$ NL is designed to execute predefined scripts across the simulation network computers, allowing its users to load all the distributed elements of a simulation from a single station, with the click of a button. Regardless of the programs needed to be loaded for the simulation, Orchid® NL will dispatch the load and unload commands across the network, including the plant model on the simulation server and the simulator HSIs on several clients.

The Orchid® NL load option ( $\left.{ }^{-}\right)$, when clicked, brings up a load window as shown in Figure 16. This load window includes several options, such as:

- Simulation Servers option, under which different plant simulator models available on the server are listed;

- Configurations option, which lists vendor specified configurations (e.g., configurations for different types of simulator displays such a panels vs. workstations);

- Templates option, which lists vendor specified settings for each configuration under the configurations option (e.g., Hive for linked panels vs. No Hive for independent panels);

- Load Options, which are used primarily for special features such as debugging. 
For example, by selecting the LoadTI with_Hive option under Templates, panels on the client side are linked, as shown in Figure 17, such that if the user navigates to a particular set of control systems on a particular control panel, then adjacent L-3 panels adapt to the change automatically to display control systems adjacent to the selected set of control systems, thereby providing continuity. Figure 17 shows the overview of the L-3 plant simulator model with different portions of the control panel CR57 highlighted. The entire CR57 control panel is displayed across three L-3 panels. If the user switches any other control panel on the overview, the display on all the three L-3 panels will adjust automatically.

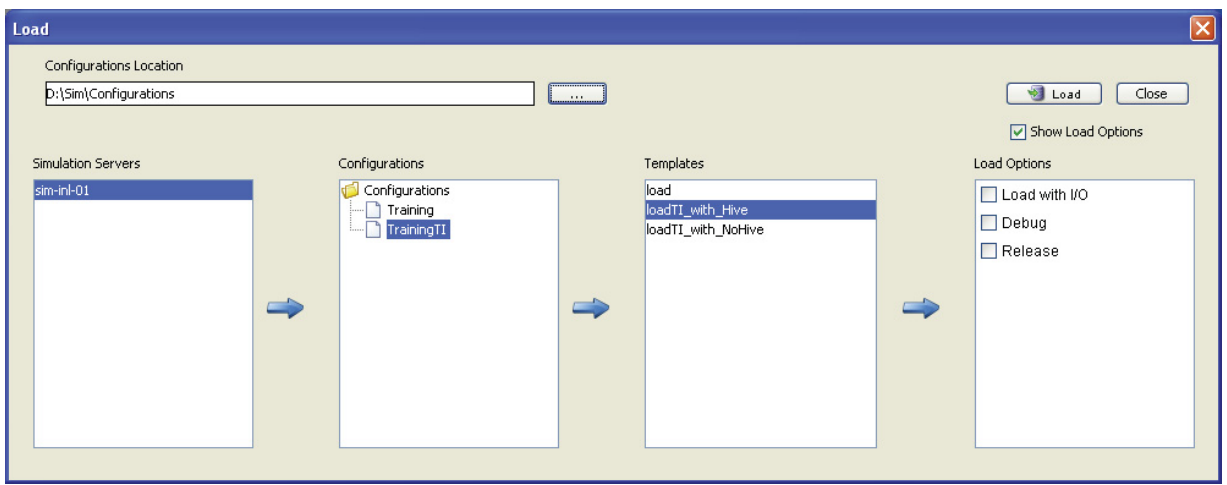

Figure 16. Orchid ${ }^{\circledR}$ Network Loader with Different Simulator Options.

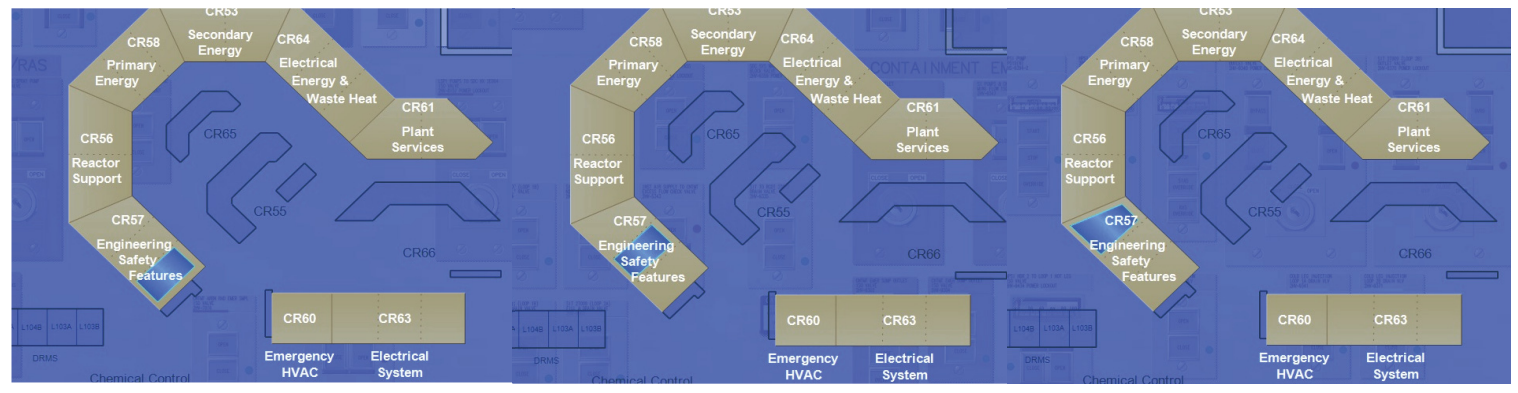

Figure 17. Controls on Panel CR57 Displayed on Three Different L-3 Panels Using the L-3 Hive Mode.

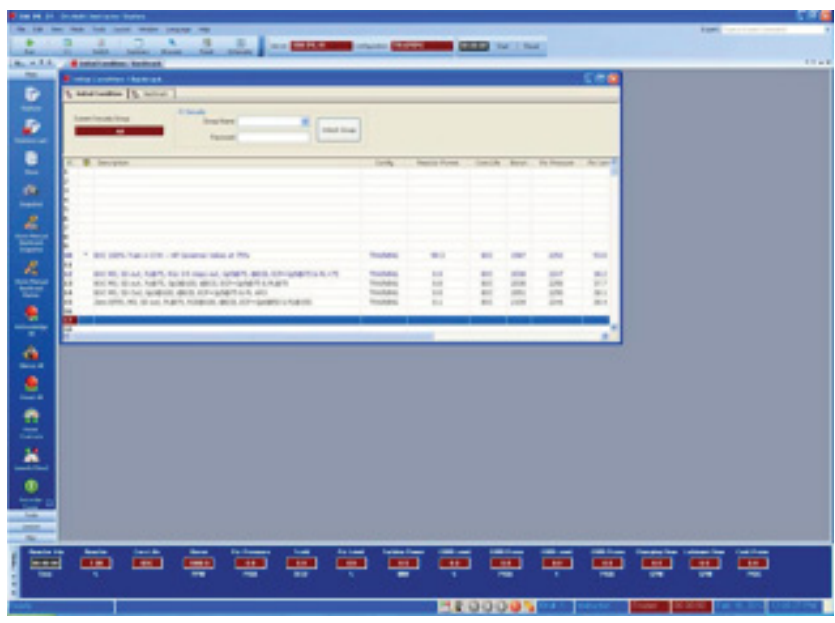

Figure 18. Default Orchid ${ }^{\circledR}$ Instruction Station Window. 
Orchid ${ }^{\circledR}$ Instructor Station, as shown in Figure 18, is designed to assist the instructor in controlling the training environment while monitoring all aspects of trainee and simulator performance. It also provides a graphic package that reflects plant states in real-time, using symbols, readouts, and colors to represent the current simulation status. Orchid ${ }^{\circledR}$ IS provides several options to the station manager which includes scenario automation, malfunctions triggering, and data logging including operator action report generation.

\subsection{GSE Simulator Platform}

The GSE plant simulator platform is also based on the client-server network architecture as discussed in Section 3.1. In terms of the client-server setup, some of the key differences between the L-3 plant simulator platform and the GSE plant simulator are:

- The GSE simulator platform does not have a dedicated network loader for overall management of software over the network. The GSE simulator platform relies instead on built-in Windows serverclient protocols, which must be manually configured by the user. This allows considerable flexibility and customization, but the initial configuration can be more involved than in the automated L-3 network loader.

- The GSE plant simulator client has to be loaded independently on each panel.

- The GSE clients are not linked. So, each panel operates independently to display different controls across different panels. In addition, the GSE plant simulation models do not scale automatically to the display resolution and size, although the displays can be easily configured during initial setup.

The GSE client uses photo-based images for its displays, while L-3 uses vector-based (i.e., drawn) images. The difference is that the GSE simulator has a more photorealistic appearance. However, the graphics cannot be scaled as readily as vector-based graphics. In addition, the photorealistic rendering, in particular the panning movement on each panel, is graphically intense and requires high-end graphics capabilities of the panel hardware.

\subsection{Configurability}

Configurability is one the key features of the LWRS full-scale, full-scope digital mockup of conventional analog nuclear power plant control room. This feature allows the user to switch between different simulator vendors and between different plant-specific simulator models. To achieve configurability, the Free Open-source Ghost (FOG) solution and Virtualization of Server (Hyper-V) are used in the clientserver software architecture.

\subsubsection{Free Open-source Ghost (FOG)}

FOG is a Linux based, free and open-source client drive cloning and imaging solution for Windows that ties together several open-source tools with a web interface. FOG doesn't use any boot disks or CDs; everything is done via TFTP (Trusted File Transfer Protocol) or PXE (Preboot eXecution Environment). An overview of FOG system is shown in Figure 19. All computers on the network should have a PXE boot as their first boot device; then FOG will chose if the machine should boot to the local hard disk or replace the contents of the disk with an image, which has been previously stored. In the example diagram, the FOG server is pushing a disk image of the GSE Harris plant simulator to the clients. The manager is the machine that controls all the tasks of the FOG server. The manager can be any web-enabled device. 


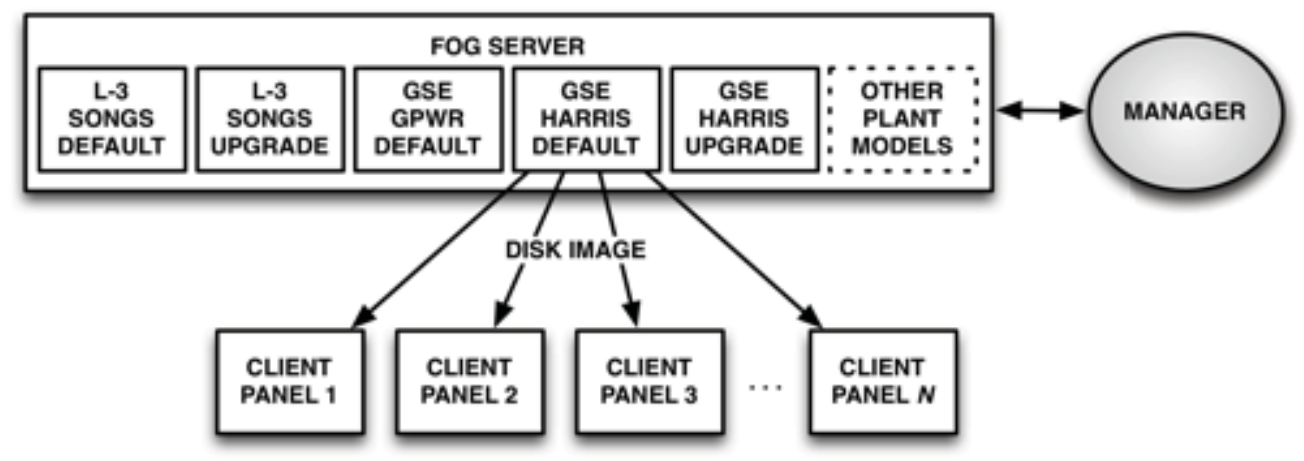

Figure 19. FOG System Overview.

FOG enables the user to push disk images with different configuration information to different client computers, or disk images with different configuration information can be stored in FOG database for later use. This immediately provides an advantage over the traditional partitioning of hard drive, as the FOG system can grow, i.e., it can be broken down and run different clients to maximize performance. In addition, FOG is a centralized system that allows users to update all clients connected to the FOG server via a single FOG file. This process greatly simplifies updates to simulators, especially when the simulator clients are identical. FOG can customize the content needed to vary between different clients (e.g., computer name and configuration files) and update this information on top of the common disk image shared across clients.

Utilizing the above-mentioned features of the FOG system, an image of GSE and L-3 simulator models with different configuration settings is stored in the FOG database. By using the FOG web Graphical User Interface, the HSSL simulator is able to switch rapidly between GSE and L-3 plant models with different configurations. Additional plant models can be added in a manner only limited by the size of the FOG server drive capability. Also, it is possible to add new simulator vendor platforms (e.g., Western Services Corporation's simulator platform) in the future. The practical consideration is that different configurations don't have to be linked to different client drive partitions a priori; it is possible simply to build new runtime drive images and install those as needed on the client panels.

\subsubsection{Virtualization of Server - Hyper V}

We are in the process of virtualizing the server side of the client-server model. Virtualization of the server enables the user to develop a server environment that can be used to support different plant simulators (e.g., Harris plant simulator and gPWR plant simulator within GSE) and different simulator platforms (e.g., GSE and L-3) on a single hardware server. The servers operate virtually on the same hardware, meaning it is possible to run multiple platforms concurrently. In addition, virtualization of the server supports OPC (OLE for Process Control server) servers that support external or secondary digital control systems (e.g., an OPC server for the Honeywell DCS system). Thus, one high-powered server system can run not only the plant model but also the ancillary servers such as the DCS required to run a full-fidelity simulation. 


\subsection{Summary}

In this chapter, high-level descriptions of the L-3 and GSE plant simulator models based on the clientserver network architecture were discussed. Today, the plant simulator models are loaded on the same sever and configured to display different control boards across different glasstop panels. The transition between the two simulator platforms is achieved using the FOG solution. In addition, differences between the L-3 and GSE plant simulator models were highlighted. 


\section{EXAMPLE APPLICATION}

\subsection{Introduction}

This section of the report recounts a current and ongoing application of the HSSL. It should be noted that one application of the simulator is already described in the earlier LWRS report, Applying Human Factors Evaluation and Design Guidance to a Nuclear Power Plant Digital Control Room (Ulrich et al., 2012). That report was completed while the simulator was still being built, limiting the authors to using the fullscope simulator on workstation displays. That report chronicles a human factors evaluation of an existing DCS for the chemical volume control system (CVCS) at a PWR. The report walked through the process of using subject matter experts to evaluate the prototype DCS against usability heuristics - a type of checklist of factors to consider for optimal HSIs. The review identified 167 potential usability issues with the DCS, although it must be stressed that none of these issues were considered safety critical. The issues represented inconsistencies in the interface against human factors standards and best practices as well as opportunities for refinement. A set of nine recommendations for improvements was made, and examples of the redesigned HSI were provided.

The previous application showed the value of using the HSSL simulator for evaluating and improving the design of the DCS to be used in a plant. However, the full advantage of the simulator for control room modernization is now being realized in a research effort in cooperation with Duke Energy Progress. Duke Energy Progress is incorporating a DCS into the main control room at its three nuclear plants: Shearon Harris, Brunswick, and H.B. Robinson. The DCS will replace legacy computer systems like the plant process computer (PPC) and the Emergency Response Facility Information System (ERFIS). In addition, new functionality is planned, notably a new digital turbine control system (TCS). In support of those upgrades, a complete human factors engineering (HFE) process modeled after NUREG-0711, Rev. 3, Human Factors Engineering Program Review Model (O'Hara et al., 2012), is being completed. The rest of this chapter outlines this process, highlighting the key areas where the LWRS simulator is being used to support this activity. This section does not provide the research findings of the process-only the important points where the simulator was used.

The near-term use of the HSSL simulator for control room modernization supports immediate industrywide needs. Using the simulator for development and validation also aligns DOE competence, thereby serving as a crucial stepping stone to long-term research with the simulator as described in Section 1.6.

\subsection{HFE Phases}

NUREG-0711 prescribes four phases for HFE (see Table 2). Each phase consists of one or more elements. Each element contains a description of the review criteria applied by the NRC HFE staff to assess the acceptability of an applicant's submittal regarding safe plant operation. Note that it is anticipated that many digital upgrades will mimic the functionality of analog system they are replacing and do not require license amendment for such modernization. Additionally, most modifications specifically are not targeted at modifications to Class $1 \mathrm{E}$ safety systems at the plant and would not fall under a requirement for license modification (U.S. NRC, 2006). However, the HFE process outlined in NUREG-0711 represents industry best practice and serves as a template for control room modifications, even if those modifications and upgrades do not require a license amendment under 10 Code of Federal Regulations (CFR) Part 50, "Domestic Licensing of Production and Utilization Facilities," Section 59, "Changes, Tests and Experiments" (U.S. NRC, 2000). This chapter describes activities already performed using the simulator as well as the planned HFE activities that follow the NUREG-0711 process. 
Table 2. HFE Phases Covered in NUREG-0711, Rev. 3.

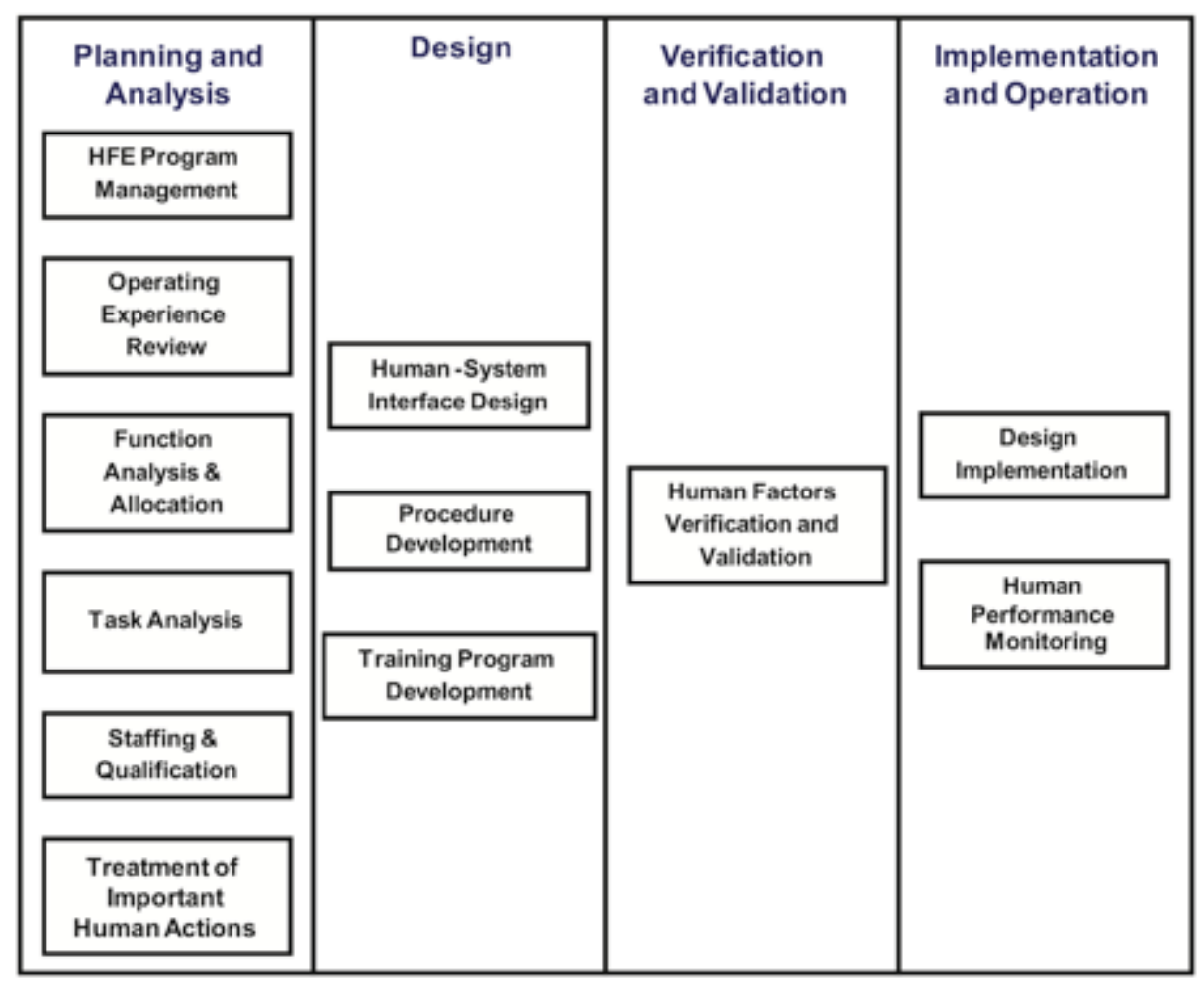

The work described herein is part of a larger research program that aims to develop methods and processes, applying the NRC HFE phases to develop standardized approaches to control room modernization that comport to existing regulatory approaches. This research also provides an opportunity to develop insights and lessons learned from such efforts across individual nuclear power stations and plant vendors that are of use and value to a broad constituency of operating nuclear plants. The partners in this effort include three plants - Harris, Robinson, and Brunswick NPPs - and involved PPC, ERFIS, and TCS replacement. Initial activities have been completed or are in progress for some of the HFE elements involved in the four NUREG-0711 program phases. Completed or in progress element efforts include HFE Program Management, Operating Experience Review, Function Analysis and Allocation, and Task Analysis - which are part of the Planning and Analysis phase. By request of the Duke Energy Progress project management team, two elements were excluded from the that initial phase. These out-of-scope elements were:

- Staffing and Qualifications - which are not currently subject to change due to any modifications to the PPC or TCS;

- Treatment of Important Human Actions (formerly Human Reliability Analysis in NUREG-0711, Rev. 2) - the safety impact of which was also determined not to change due to any modifications to the PPC or TCS.

Simulators were used for the Function Analysis and Allocation and Task Analysis elements of the Planning and Analysis phase and will be used as part of all subsequent phases. 


\subsection{Simulator Use in the Function Analysis and Allocation and Task Analysis Workshop}

\subsubsection{Functional Requirements Background}

As part of the systems engineering process, HFE activities for system upgrades as well as new designs focus on the role and function of humans as key elements in the industrial process. The human-centered analysis of systems and operations integrates the three elements of functional requirements, function allocation, and task analysis to establish design requirements for an HSI design, which, in nuclear power plants, forms part of the control room. The system and operations analysis addresses operational aspects of the plant by systematically defining equipment, software, personnel and procedural data requirements that meet all functional objectives of the control room and its operating crew, including safe operation of the plant. It assists in determining the design of the plant and specific systems, particularly the control room HSI and its components required for safe plant shutdown. The various phases of this analysis collect parameters concerning the plant (and its various systems) and identify those required for the operating crew monitoring, cues for action, and feedback on actions taken. The analysis also identifies the main control and operating options available to operators for safe and economic plant operation. The plant processes that should be placed under operator control, and their relationship to each other, are also revealed. Several phases of the HFE process necessary for control room upgrades are depicted in Table 3.

Table 3. Main Phases of Human Factors Engineering and Underlying Goals.

\begin{tabular}{|c|c|c|c|c|c|c|c|}
\hline & $\begin{array}{l}\text { Function } \\
\text { Allocation }\end{array}$ & $\rightarrow$ & $\begin{array}{l}\text { Task } \\
\text { Analysis }\end{array}$ & $\rightarrow$ & $\begin{array}{l}\text { Design } \\
\text { Activities }\end{array}$ & $\rightarrow$ & $\begin{array}{l}\text { Verification } \\
\text { and } \\
\text { Validation }\end{array}$ \\
\hline ڤัٌ & $\begin{array}{l}\text { What is system vs. } \\
\text { operator controlled? } \\
\text { Identify opportunities to } \\
\text { improve performance } \\
\text { by indentifying } \\
\text { modifiable functions. }\end{array}$ & & $\begin{array}{l}\text { What can be } \\
\text { changed? Define } \\
\text { information and } \\
\text { control needs for } \\
\text { operators to perform } \\
\text { new and existing } \\
\text { functions. }\end{array}$ & & $\begin{array}{l}\text { What's the new } \\
\text { design? } \\
\text { Develop } \\
\text { conceptual } \\
\text { designs for the } \\
\text { HSIs. }\end{array}$ & & $\begin{array}{l}\text { Does it work? Test } \\
\text { the designs and make } \\
\text { sure all required } \\
\text { information and } \\
\text { controls are there and } \\
\text { work. }\end{array}$ \\
\hline
\end{tabular}

A function is defined as the operations that must be performed by one or more systems in order to meet the mission goals of the plant. These functions may either be executed automatically by an automation system or initiated manually by the operator by means of the HSI. Note that functions may refer to diagnosis activities such as gathering information and activation of controls. Thus, automation may pertain to consolidating relevant indicators into operator displays or to actually controlling the plant.

The functional requirements analysis (FRA) process typically consists of high- and low-level analysis phases required to define a system's functional architecture in terms of the operations that must be performed in order to meet the mission goals of the system. In the high-level analysis, system functions are partitioned into requirements for sub-system functions. For a new system, no specific allocation is made yet to hardware, software, or humans. The allocation is based on the overall operational requirements and system mission. However, since the PPC is a known system with functions already well-defined by both the vendor and user, the FRA part of the workshop focused only on identifying those functions that, due to the nature of operators' anticipated interaction with the system, might be 
targets for improvement. In a low-level functional analysis, the aim is to decompose the high-level functions into a coherent set of executable functions associated with operational conditions or modes and specific systems and major components. The goal of the functional analysis at this level is to determine the functions that are associated with high-level operational goals and to create a framework for an understanding of the relative role of human, or system controllers. Again, due to the fact that the PPC is the de facto system chosen to present predetermined classes of information to the operator, only those functions identified in the high-level analysis are selected for further analysis.

Function allocation (FA) is an analytical process that distributes defined functions between available resources (humans, hardware, software or combinations). The allocation of some functions will be mandatory and predetermined by constraints established during the requirements analysis phase.

Allocation is also determined by comparison of performance between humans, hardware, software, cost factors, and cognitive support for operators. Allocation decisions are made to maximize total system performance and effectiveness, taking into consideration the contextual capabilities and limitations of systems and humans.

\subsubsection{Functional Requirements Workshop}

In preparation for the FRA/FA workshop, a series of scenarios were developed that included use of the existing PPC and ERFIS systems that will be replaced by a DCS. These scenarios also made use of the turbine, for which a TCS replacement system is being developed. The FRA/FA workshop was conducted in November, 2012, at the HSSL. At the time, only the first six glasstop bays were available in the simulator facility as shown in Figure 20. These panels were configured to represent the Harris and

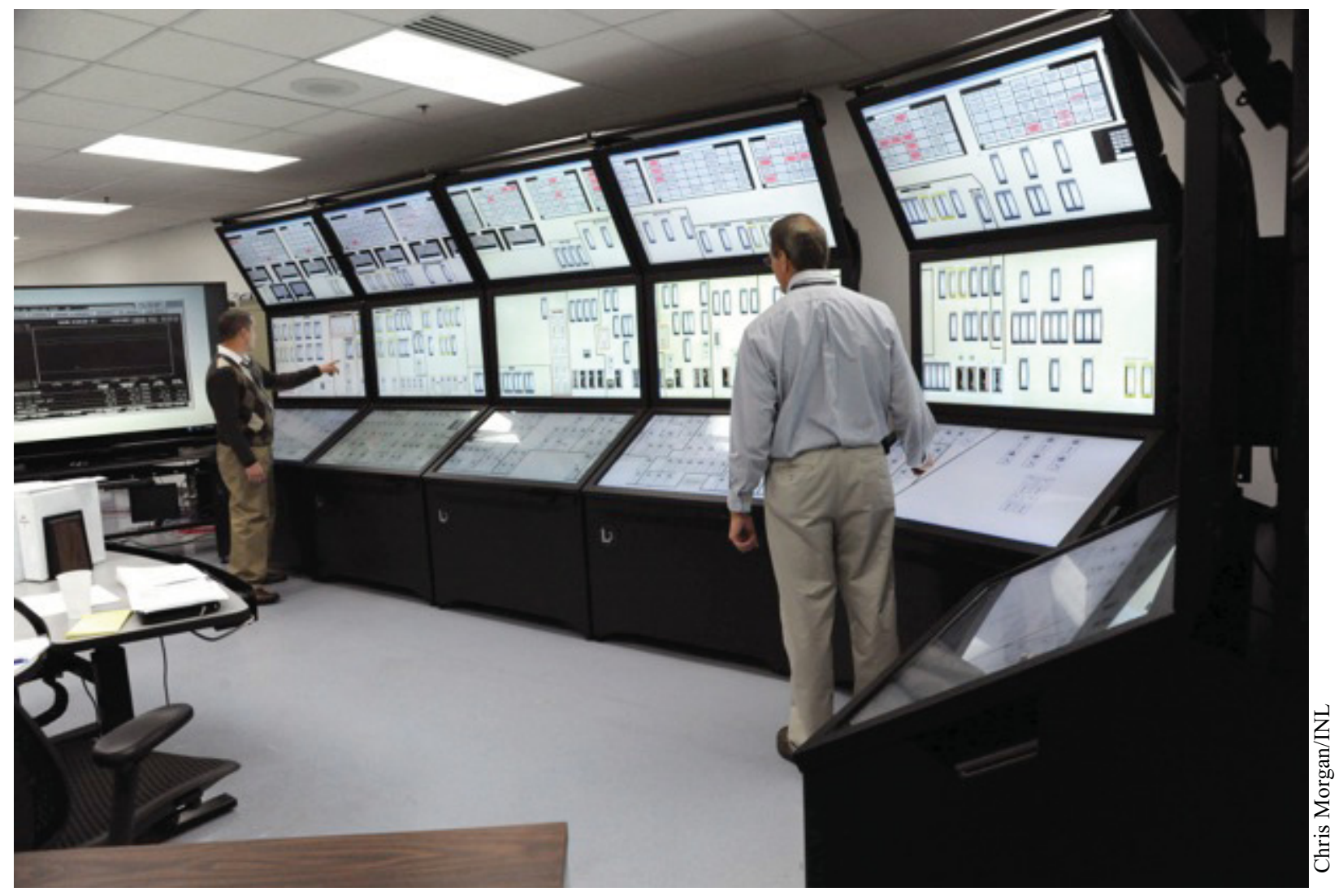

Figure 20. The LWRS Simulator Configuration Used for the FRA/FA Workshop. 
Brunswick main control board presentations. An 80-inch display was provided to the left of the six panels. Various static display screens, e.g., ERFIS and PPC for the Harris walkthroughs, and procedures could be selected by the operator and viewed on this display at appropriate times during a scenario walkthrough.

Operators from the Brunswick and Harris NPPs performed the scenario walkthroughs separately. Harris operators performed scenario walkthroughs first. One operator was at the simulator control boards, and a second operator served as procedure reader. A third person from Harris familiar with more advanced HSIs based on experience in non-nuclear plants observed and provided suggestions regarding technology capabilities. One Brunswick operator performed scenario walkthroughs following completion of the Harris sessions. Observers, including HF engineers, an HFE consultant, an engineer from the Halden Reactor Project, and an engineer from Duke Progress Energy, recorded and later analyzed the functions and function allocations identified during the walkthroughs.

A table and chair were placed in front of the simulator bays, providing a location for the operator serving as a procedure reader or senior reactor operator during the Harris scenario walkthroughs. The Brunswick NPP operator held and read the procedure during each scenario walkthrough. Chairs and tables were provided for personnel observing and collecting HFE performance data and comments during the scenario walk-throughs. Figure 21 shows the arrangement. Post-scenario debriefings were conducted at the same location as the scenario walkthroughs.

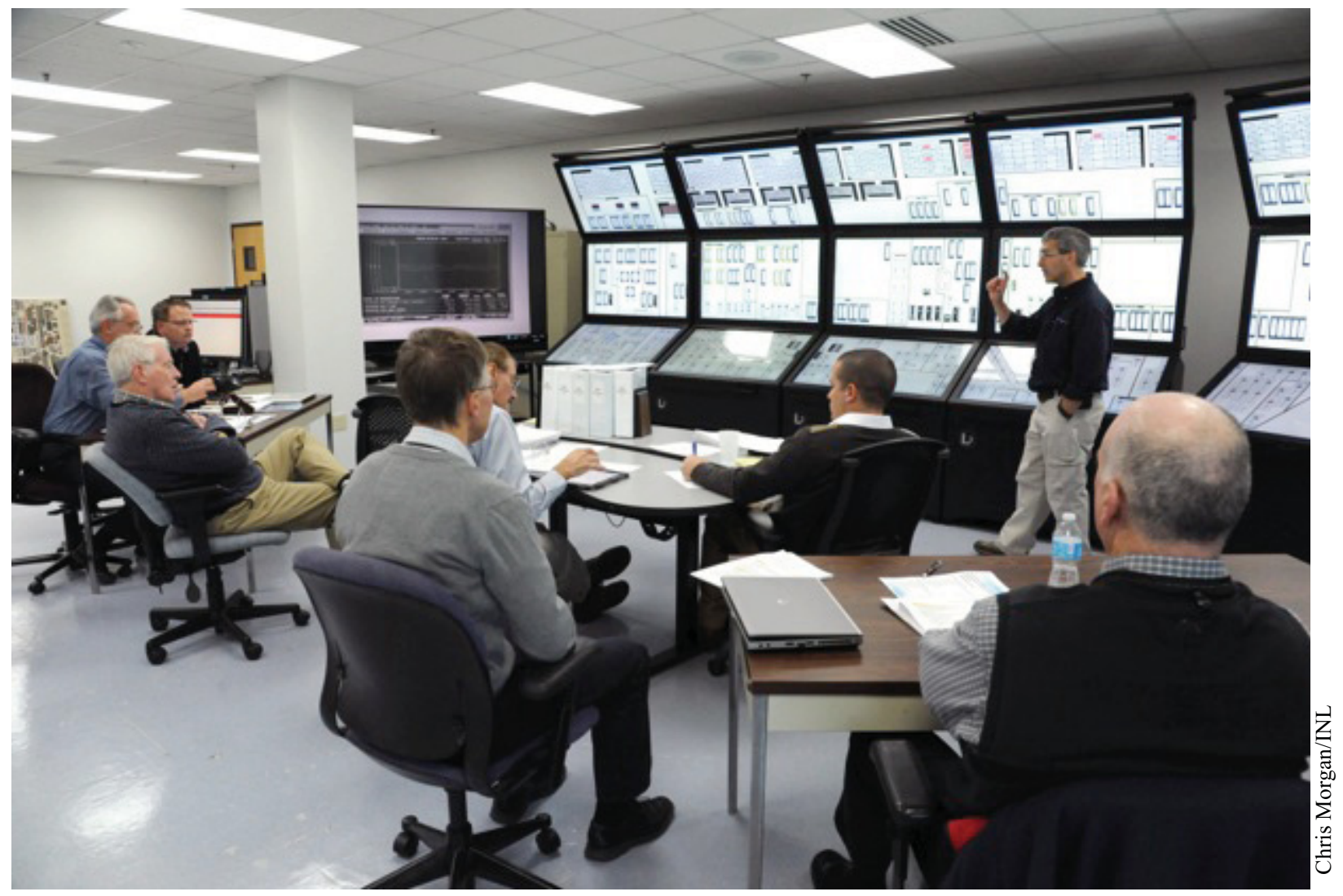

Figure 21. Observation and Debriefing in the Simulator. 
Exitech Corporation, the simulator vendor used by the Brunswick Nuclear Plant, does not currently offer a glasstop solution for their simulators. Since no glasstop simulator software was available for the Brunswick scenario walkthroughs, a workaround was developed consisting of graphical representations of the Brunswick control boards displayed on the glasstop panels. The images obtained for the Brunswick control boards were produced from the engineering schematics used for the control board layouts. Although these images did not feature the near photorealism of the Harris simulator, they were accurate representations of the appearance and location of the instruments and controls on the control boards. The images were "stitched together" to form a reasonably seamless representation of the control board layout and arranged to enable display of as many sections of the control board as would fit onto the six glasstop panels. The control board graphics could be scrolled to allow the operator to view any panel from the control room. Figure 22 provides a photograph of the Brunswick control board representation.

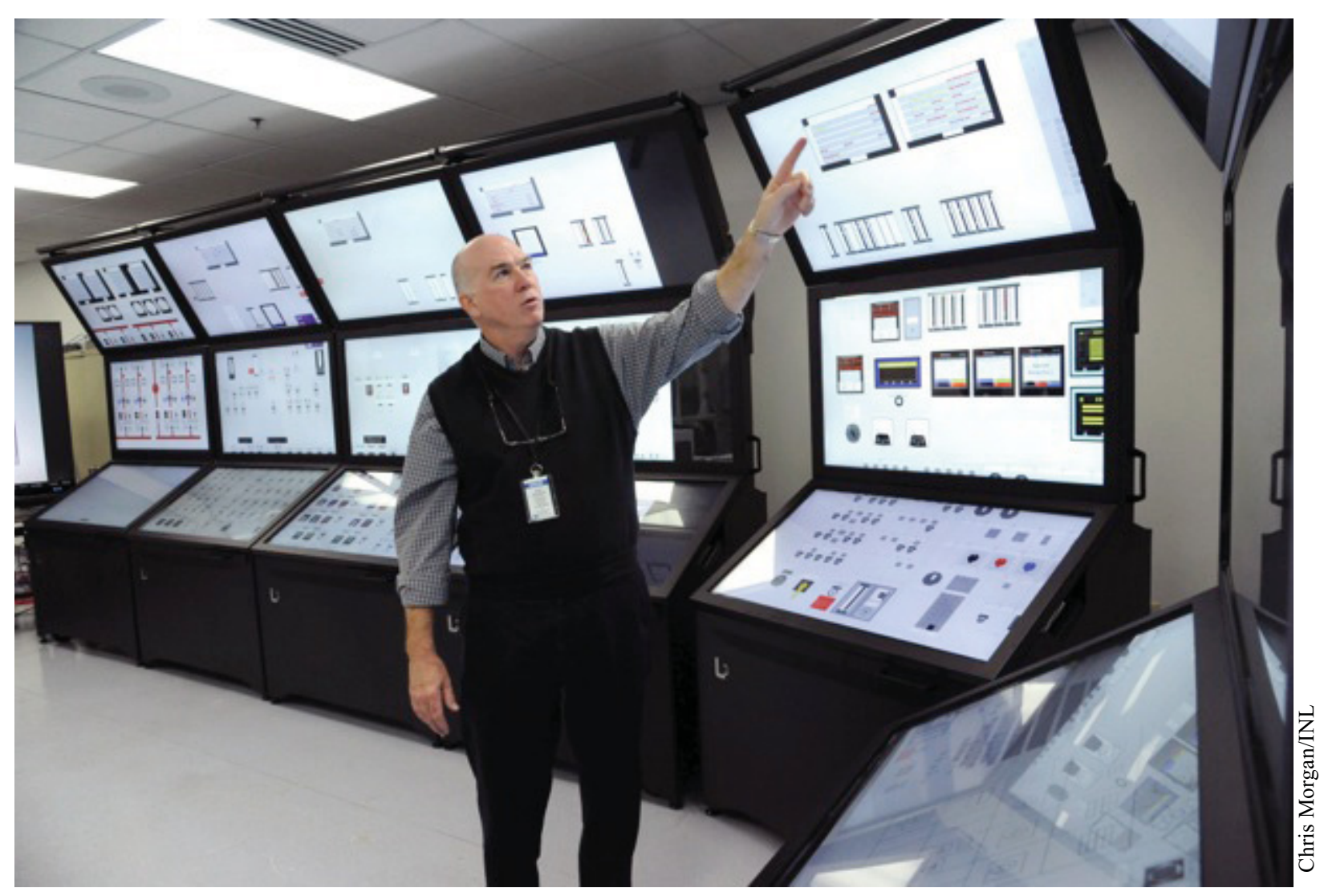

Figure 22. The Brunswick Simulator Displays.

Since only six panels were available for the workshop, not all of the control board panels normally viewable by the operator were available simultaneously during the walkthroughs. The panels were set at the start of each scenario to show the six control boards used most frequently during the scenario. The control board panels used less often and not viewable on the six panels at the beginning of a walkthrough were accessed by navigating left or right from any of the panels.

It was initially planned that the panels would have picture-in-picture capability. This capability would allow the panels to show not only the virtual control boards but also the dynamic displays associated with current computer systems like the PPC and ERFIS. Unfortunately, this capability could not be 
implemented for this workshop due to simulator vendor limitations. ${ }^{2}$ As such, the large display to the side of the panels was used to show PPC or ERFIS displays.

Both Brunswick and Harris NPP operators were generally satisfied with the HSSL simulator and agreed that it offered functionality appropriate to the objectives of the workshop. The limitations of the simulator configuration prevented some detailed analyses, especially for the Brunswick scenarios. However, participants agreed that these limitations did not detract significantly from achieving the workshop objectives, i.e., identifying key functions and opportunities for refining the allocation of those functions to either operator or automation. Operators would have preferred a full-scale representation of the control room, but stated that the six panels were adequate for the purposes of the workshop. The HFE team expressed concern that the deficiencies identified above may have influenced the results by requiring operators during walkthroughs to spend too much time and attention on the mechanics of obtaining the needed information (e.g., scrolling to the right panel location) and taking appropriate control actions. In other words, the lack of full scale for the simulator and the lack of embedded computer displays for PPC and ERFIS reduced the fidelity of the walkthroughs. For that reason, it was decided to conduct the task analysis workshops at the actual plants, in order to compare the results from the glasstop simulator with those of the actual plant training simulators.

\subsection{Simulator Use in the Task Analysis Workshops}

Task analysis defines the information, control, and human performance requirements for various operational scenarios. Separate task analysis workshops were conducted in December, 2012, at Shearon Harris Nuclear Plant and in February, 2013, at Brunswick Nuclear Plant. The workshops aimed to identify and analyze the specific tasks that need to be performed by operators to accomplish the requirements of specific as well as general operational conditions. The ultimate aim of the Task Analysis phase of the control room upgrade is to develop high-level sequential descriptions of the operations that must be carried out to fulfill the functions of a particular system. A task in this project is defined as a group of related activities with a common objective, often occurring in close temporal proximity. The results of task analysis serve as inputs to subsequent phases of the NUREG-0711 based process. Crews at the respective plants ran through the same scenarios as at the HSSL for the FRA/FA workshop.

Additional scenarios were developed to test specific interactions with the PPC and ERFIS. As in the FRA/FA workshop, the crews were observed by trained HFE and plant observers. The crews were subsequently debriefed to identify operator performance requirements for the scenarios. The information from the scenario walkthroughs and debriefs was recorded in operational sequence diagrams, which map the operators' interactions with the various systems in the control room. An example operational sequence diagram for one of the scenarios is depicted in Figure 23.

Since the Task Analysis workshops were conducted at the actual plant simulators (see Figure 24), this allowed a comparison of the operator experiences using the hard panel simulators at the plants' training centers vs. the glasstop simulator at the HSSL. However, since a glasstop simulator was not available for the Brunswick plant, no direct comparison was possible to the plant training simulator. Below is a comparison of findings for the Harris plant training simulator vs. the glasstop implementation with six panels at the HSSL:

- Navigation - It took longer to find information in the glasstop simulator because it did not represent the full scale of the control room. Operators remarked that they could not respond as quickly as in the actual control room because of the need to scroll to the required panel. Operators expressed that the

\footnotetext{
${ }^{2}$ The picture-in-picture capability has subsequently been implemented on the GSE Systems simulator.
} 
Small Leak in Containment

This scenario requires the operators to respond to a small leak inside CNMT not requiring Reactor trip or Safety Injection Applicable Procedures: AOP-016, Attachment 7

Applicable Procedures: AOP-016,

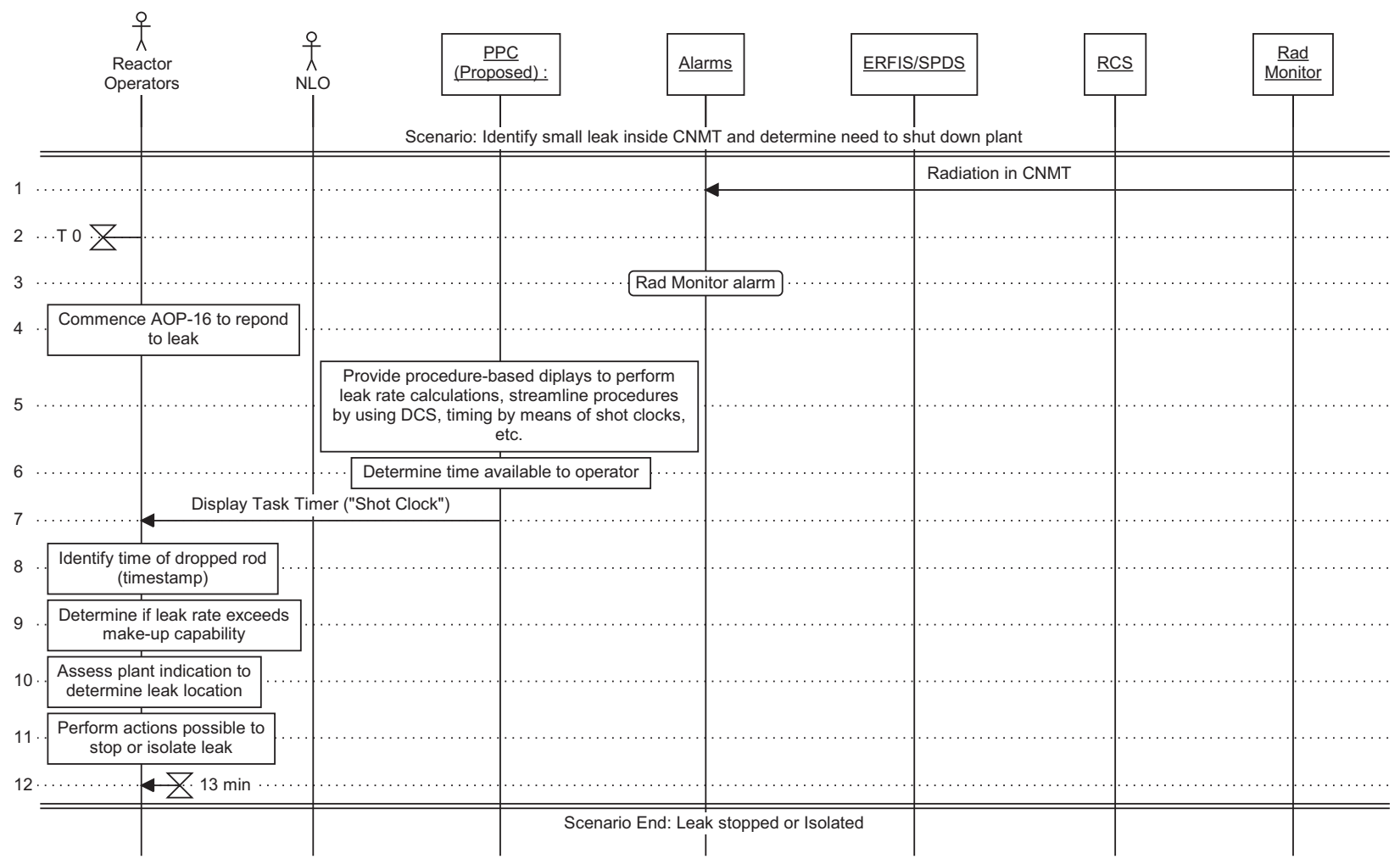

Figure 23. Sample Operational Sequence Diagram for a Simulator Scenario.

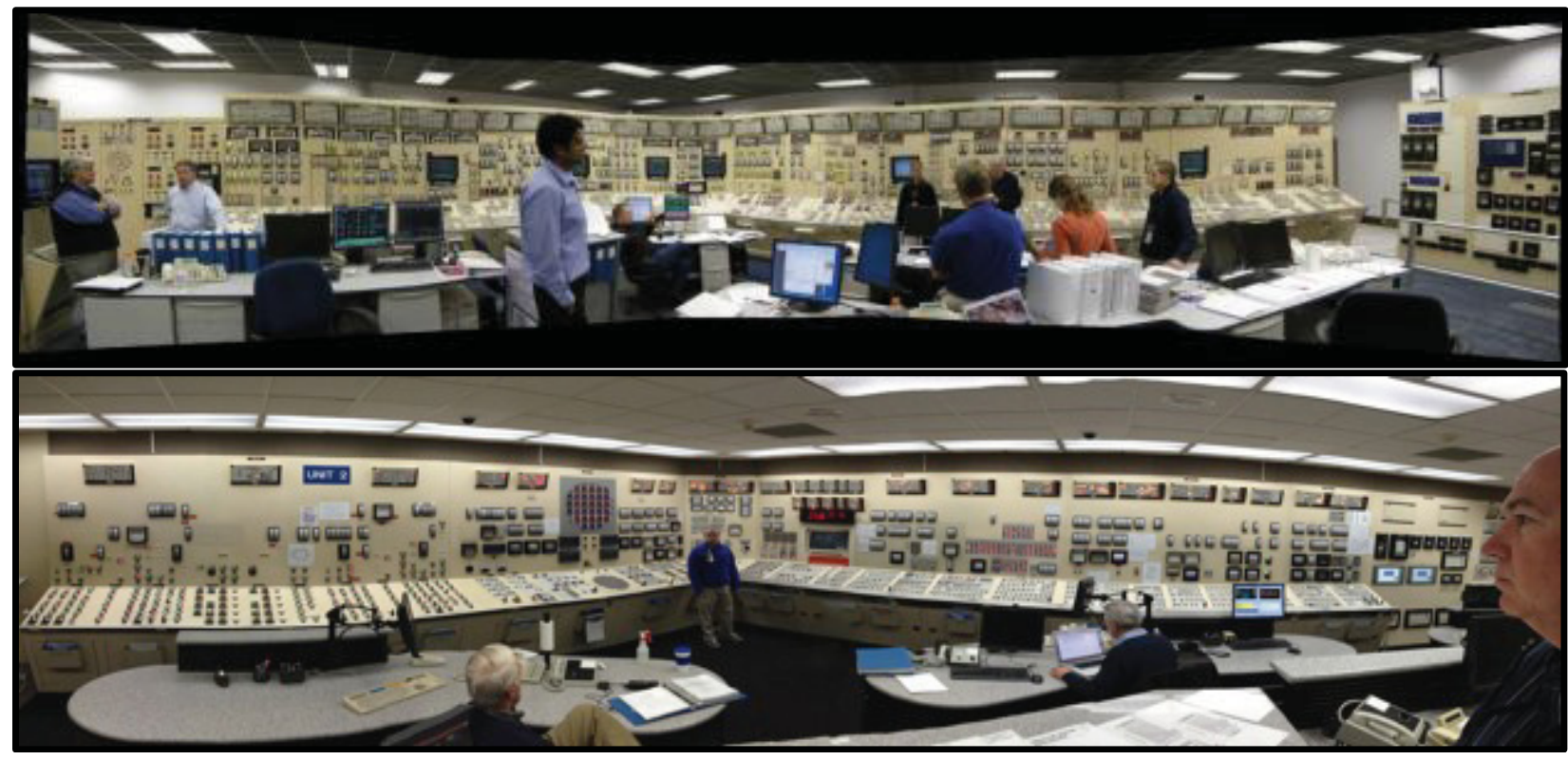

Figure 24. Actual Training Simulators Modeled on the Glasstop Panels. 
scroll or swipe method proved cumbersome, and an overlay map for quick navigation to the desired panel would greatly enhance the usability of the glasstop panels. ${ }^{3}$

- Lack of embedded displays - Since live PPC and ERFIS displays were not available where they would normally reside on the control panels, this created an unnatural experience interacting with the control boards and required looking at a separate display. This functionality - the form of picture-inpicture technology - is newly available for the simulator, although it was not at the time of the scenario walkthroughs.

- Operator aids - Operators frequently use a variety of operator aids, from stopwatches to magnetic boards (e.g., "hard cards") that can be placed on the control boards to log information. Stopwatches were not provided during the HSSL walkthroughs, although these are readily available for future use. The glasstop simulator displays do not currently support virtual placement of operator aids on the panels.

- Tag outs - While it is possible to place Post-It notes for tag outs on the panel displays, their placement only holds as long as the display panel are locked in a static position relative to the control boards at the plant. There is currently no provision to place virtual tag outs on the display panels that would move with any repositioning of the virtual panel position.

- Procedure placement-The control boards at the plants feature mounted alarm response procedures. The hardware of the glasstop panels was not optimized to the corresponding placement of procedures at the actual plant. However, each plant features slightly different placement of the procedures, and a reconfigurable hardware augmentation to the glasstop panels is not likely. In addition, it is common to place procedures temporarily on the benchboard of the physical panels at the plant. Because of the touchscreen functionality of the benchboard display, it is not possible to place a procedure on the display without inadvertently activating some touchscreen functions.

- Responsiveness - There were several cases when the touchscreen did not immediately recognize an operator touch. This problem appears to be a combination of occasional system lag coupled with touchscreen miscalibration. This problem may be possible to rectify to some degree by optimizing the configuration of the simulator software and hardware; however, it is not uncommon for commercial touchscreens to experience some calibration and response issues (e.g., touchscreen voting systems have received international press coverage for the foibles of miscalibration on a multiple choice voting form).

- Layout - Operators reported being aware that the physical layout of the LWRS simulator was different than their home plant control room. Because the control boards represent a contiguous layout, the operators adjusted quickly to the layout of the control room and were able to mentally map the placement of the plant panels to the virtual panels. This was evidenced by the ability of the operators to look in the right place for information on the glasstop panels, even when the glasstop panel placement differed from the physical layout of the actual plant. Proprioception is the term used to describe the relative awareness of the body - in particular, body position - to the external world. While this term is used primarily for kinesiology, it holds merit in the context of the operator's awareness of his or her position relative to the control panels. The proprioception relative to the control panels exhibited flexibility in this study.

These differences did not encumber the ability of the operators to use the glasstop simulator. In fact, no glasstop specific training was provided, and the operators treated the controls rooms interchangeably without an evident learning period. Each of these differences warrants further investigation, and the differences are presented here anecdotally from observation and operator comments rather than through a carefully controlled scientific benchmark. To better understand these differences, a formal benchmark or validation exercise of the glasstop simulator to the plant training simulator is planned in the future.

\footnotetext{
${ }^{3}$ This functionality is found in some simulator vendors' software.
} 


\subsection{Moving Forward: Design, Verification and Validation, and Implementation Phases}

The Planning and Analysis phase of NUREG-0711 has been completed for both Harris and Brunswick plants. Further work is underway to complete the FRA/FA and Task Analysis for the Robinson plant, completing the Planning and Analysis phase for all NPPs planned for neary-term DCS and TCS upgrade under Duke Energy Progress. Additionally, work is scoped to use the LWRS simulator in support of the remaining phases of NUREG-0711: Design, Verification and Validation (V\&V), and Implementation.

\subsubsection{Planned Simulator Use for the Design Phase}

As described in NUREG-0711, Rev. 3, "The HSI design process represents the translation of function and task requirements into HSI characteristics and functions." This section explains how previous work performed in the Planning and Analysis phase feeds into the actual design of the HSI. Specifically, this section considers how an existing analog system on the control panels, the TCS, is being converted to a DCS.

As depicted in Table 4, the elements of the Planning and Analysis phases each provide key information that is used in the design of the new HSI for the control room. This general information is combined with a specification for each HSI display used in the DCS. The specification may be developed according to the migrated vs. new HSIs. Migrated HSIs are those in which a legacy computer system like the PPC or ERFIS is mapped to a new DCS platform. New HSIs represent DCS functionality, like the TCS, that did not previously exist electronically in the control room. The discussion here centers on using the simulator in support of developing new HSIs. A key assumption is that the DCS HSI will take the place of existing displays or standard I\&C on the control boards. This discussion does not consider additional topics relevant to migrating from the control panels to workstations or other advanced HSIs beyond the control boards.

Table 4. Use of HFE Program Elements in HSI Design.

\begin{tabular}{|l|l|}
\hline HFE Program Element & Use in the HSI Design \\
\hline Operational Experience Review & $\begin{array}{l}\text { Lessons learned on previous system use and } \\
\text { identification of important human actions }\end{array}$ \\
\hline $\begin{array}{l}\text { Functional Requirements Analysis/Function } \\
\text { Allocation }\end{array}$ & $\begin{array}{l}\text { Opportunities for automation of displays and } \\
\text { system execution; required role of operators in } \\
\text { controlling the system }\end{array}$ \\
\hline Task Analysis & $\begin{array}{l}\text { Information and tools required by operators to } \\
\text { support task execution }\end{array}$ \\
\hline HSI Style Guide & $\begin{array}{l}\text { Requirements for controls, navigation, visual } \\
\text { presentation, and other HSI elements }\end{array}$ \\
\hline
\end{tabular}

The FRA/FA and Task Analysis workshops identified new functionality that would be advantageous to the operators in the modernization of the PPC and TCS. Example new functions that were identified include but are not limited to: 
- Procedure support displays - which can be called up to support operators walking through particular commonly used or complex procedures (e.g., a display to bring up plant parameters required to step through the checklists in initial emergency operating procedure, E-0)

- Automated calculations - which currently have to be calculated manually by operators from separate and sometimes distally located indicators in the current control room configuration (e.g., leak rate calculation)

- Shot clocks - which help the operator keep track of time required for continuous action steps, including multiple simultaneous continuous actions

- Prioritized alarms - which help the operator to focus on the most safety critical tasks at hand.

These new features should be developed in accordance with a standard user-centered design method such as ISO 9241-210 (2010), Ergonomics of Human-System Interaction-Part 210: Human Centred Design for Interactive Systems, and ISO 9241-11 (1998), Ergonomic Requirements for Office Work with Visual Display Terminals (VDTs) _Part 11: Guidance on Usability. An example approach tailored for DCS design can be found below in Figure 25. The approach has five basic steps:

1. Identify the desired features and functions of the DCS display, whereby insights are extracted from the Operational Experience Review (to the extent there may be deficits in the existing HSI), the Functional Requirements Analysis and Function Allocation, and the Task Analysis. There should be a clearly documented need for the new functionality as demonstrated by an existing performance deficit (e.g., a cumbersome or error-inducing HSI) or the opportunity for operator performance improvement (e.g., increased reliability through automation or improved operator response time). While operator desires for new features may be considered, the basis for new features and functions should remain grounded in opportunities for improved reliability, safety, and performance.

2. The desired features and functions are turned into a specification. This display specification should conform to the HSI Style Guide for the DCS.

3. The specification is prototyped to a degree suitable for evaluation. The prototype can be as simple as a line sketch of the interface or involve using the DCS graphics development tools to create an early version of the final implemented DCS. The prototype should contain sufficient fidelity such that dimensions and colors can be depicted accurately. The prototype should also provide the context of operation, such as the relation of the DCS to other systems in the control room. A control room simulator serves as the ideal testbed for prototyping and evaluation. Use of a simulator to mimic DCS functionality helps ensure rapid prototyping. If the native DCS environment is used in the prototype, it is not necessary to enable all functionality. The prototype will be evaluated, and it is important that the prototyping phase not be considered the end development and deployment stage.

4. The prototype is usability tested. Usability testing is the process of assessing the degree to which the designed system can be used effectively by the target user. Success metrics range from user satisfaction to user performance. In the case of the usability evaluation of the DCS displays, the goal is foremost to ensure that operators understand the HSI elements and also can operate the HSI, from navigating between different displays in the DCS to controlling parts of the plant using the DCS. The usability evaluation is ideally formative, meaning it is used not only to verify the usability of the designed system but also to help specify the design in an iterative fashion. There are two accepted ways of usability testing: 


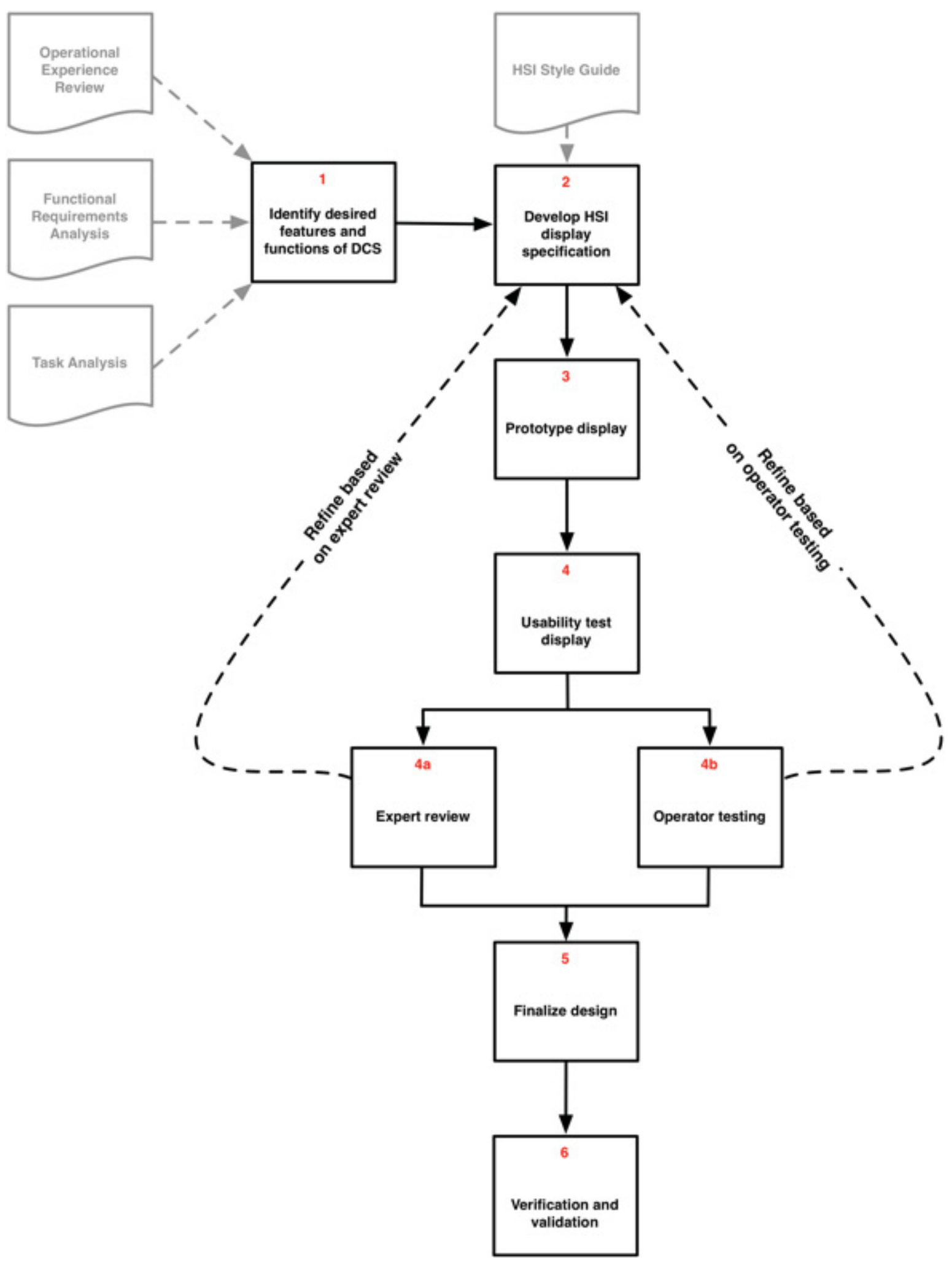

Figure 25. Flow Diagram for Developing New HSI Displays for the DCS. 
a. Expert review - in which subject matter experts in human factors, nuclear operations, or control systems review the HSI. This review may follow specific usability criteria called heuristics or provide an overall impression of how the HSI would be used and any deficiencies they might note. Expert reviews are especially useful early in the design phase, with a full-scale V\&V with operator testing conducted later in the development cycle.

b. Operator testing - which can range from walkthroughs with nonfunctional mockups to scenario testing using fully functional prototypes. The level of fidelity and functionality is a product of the resources of the design team and the degree to which the new functionality diverges from current plant operations.

Results from the usability testing phase should be used to refine the design. If there are design deficiencies, the design should be revised and the process iterated starting at Step 2.

5. The design is finalized. Once the prototype has been evaluated and it has been determined that the HSI can be used successfully and safely by operators in the control room, the design specification and supporting documentation are assembled. This information is used as the basis of implementation and should be retained for licensing support. Additionally, it is not anticipated that new HSI functionality incorporated into the control room would require a change in plant operating procedures. As the design is finalized, the adequacy of existing procedures should be evaluated and documented.

6. The finalized design will be used in the $\mathrm{V} \& \mathrm{~V}$ phase, which is documented in the next section.

As noted, the design phase includes prototyping the new HSI. While such prototyping and usability evaluation does not expressly need to be carried out in a control room simulator, the simulator affords a few distinct advantages over DCS prototyping independent of the control room:

- The position of the DCS can be optimized on the control boards. It is not readily possible to reposition displays on the actual training simulator boards, since holes must be cut out on the panels to accommodate the displays and existing I\&C must be repositioned or eliminated. The glasstop panels provide the means to try multiple layout alternatives.

- In some cases, the DCS development tools are not optimized for rapid application development, and there is considerable effort to integrate the separate DCS application with the simulator platform. This effort must be repeated at implementation phase, since the actual plant platform differs from the software architecture of the simulator. In other words, there is considerable effort to develop an integrated prototype using the DCS and the simulator. In contrast, simulator platforms like L-3 Orchid ${ }^{\circledR}$ Graphics Environment (GE) or GSE ${ }^{\mathrm{TM}}$ Java Application Development Environment (JADE) provide rapid application development tools that are already integrated into all plant variables needed for the simulation. It is arguably a more streamlined path to use these simulator development platforms for prototyping.

- When designing across a fleet of reactors, as is the case for Duke Energy Progress, the simulator provides a standardized testbed that may be used across different reactors. The use of the research simulator as the standard testbed ensures consistency in the design and evaluation of the HSIs.

It is currently planned that design work will be conducted in the HSSL. 


\subsubsection{Planned Simulator Use in Verification and Validation}

The HSI design process described in the previous section encompasses many of the HSI testing requirements for V\&V outlined in NUREG-0711. In fact, a general user-centered design approach like the previous section is explicitly endorsed in NUREG-0711, Rev. 3. The specific phase of V\&V that must be conducted independent of usability testing is ISV. Current collaborative research with Duke Energy Progress plans to use the HSSL for its integrated system validation.

The steps for an ISV on new HSIs for PPC and TCS encompass the following steps:

1. The prototyped system is implemented in a fully functional variant in the full-scope control room simulator. The glasstop simulator using the underlying plant model from the training simulator may serve as a surrogate for the actual plant training simulator. This process can avoid the need to physically modify the training simulator (e.g., change hard panels to introduce displays) until the implementation phase. Having a facility separate from the training simulator that can support ISV has a further benefit. It avoids potential conflicts between training for the plant as it is vs. the plant as it will be once modified. The training simulator is maintained as-is while V\&V are conducted on the duplicate glasstop simulator.

Note that once the design is finalized, it is advantageous to deploy the actual DCS in the simulator. The actual DCS should be embedded in the simulator to minimize the need for later detailed analysis of differences between the as-tested vs. as-deployed system. As such, the DCS should follow careful software and hardware quality assurance requirements as part of the ISV.

2. A representative sample of scenarios are selected to walk through the new DCS HSIs with operators. These should be scenarios that encompass actual use of the DCS, test operator knowledge, test operator interactions with each other in the control room, and represent potential accident sequences. Note that the scenarios previously used in the Functional Requirements Analysis/Function Allocation and Task Analysis workshops fulfill these criteria. The same scenarios that were run previously can be run during the $V \& V$ phase. These scenarios thereby also serve to benchmark operator performance before and after the new DCS HSI.

3. The DCS should be pilot tested with a group of operators or qualified personnel (e.g., not-yet-licensed reactor operators, qualified trainers, recently retired reactor operators) to ensure the proper functioning of the system.

4. Operators are trained on the use of the new DCS HSIs. A stand-alone DCS HSI training program will be developed in cooperation with the training organization. In addition, the scenarios will be reviewed by trainers and procedure writers to ensure that the operating procedures do not require modifications as used in conjunction with the new DCS.

5. Operators perform the selected scenarios using the new DCS HSI for PPC and TCS. A combination of systems engineering, HFE, and training personnel oversee the scenario walkthroughs to ensure:

- The DCS implementation functions per the design specification.

- The operators are able to complete the scenario tasks successfully (i.e., correctly, completely, within time requirements, and without confusion or misunderstandings) using the new DCS. HFE personnel will assess situation awareness and workload to ensure these are within acceptable bounds. 
More than one set of operators should walk through the scenarios, and the order of the scenarios should be randomized to ensure performance on particular scenarios doesn't simply reflect learning effects.

The results of the ISV should be documented. Any deficiencies (e.g., human engineering discrepancies) should be resolved, and those resolutions should be documented. Significant deficiencies should follow the HSI Design process in Section 4.5.1, although in most cases, a repeat of the entire ISV may not be necessary, assuming usability testing of redesigned HSIs is conducted.

\subsubsection{Use of the Simulator for Design Implementation}

As outlined in Section 4.5.2 of this report, the DCS HSI is actually completed and tested as part of the ISV process. A final phase involves installing the new DCS and HSI. During this phase, the full-scale simulator at the HSSL may not be required, although the DCS implementation in the HSSL used during the V\&V phase may be installed on corresponding training simulator and classroom glasstop simulators at the plants.

There are several stages to this installation:

1. The underlying DCS is installed in the plant simulator and plant. This installation includes any required vendor hardware for the DCS, any architectural backbone upgrades necessary to send and receive information between the DCS and plant sensors and controls, and any configuration protocols and simulator upgrades necessary to send and receive information between the DCS and the simulator. The DCS may be installed and run in background mode ahead of the HSI deployment, which provides a window in which to verify the DCS configuration integrity prior to HSI deployment.

2. The DCS HSI for PPC and TCS is deployed in the control room simulator for training purposes.

3. Operators are trained on the DCS HSI for the PPC and TCS. This training includes DCS fundamentals (operation, navigation, etc.) and specific training on the PPC and TCS. Training should include backup operations in the event of the failure of the DCS. Note that it may be possible to maintain both a legacy I\&C and DCS HSI in the training facilities until the deployment of the DCS HSI in the main control room. Glasstop simulators available at Harris NPP would be ideal for maintaining a second configuration of the PPC and TCS as long as needed. All operators should receive the DCS training prior to HSI deployment in the main control room.

4. The PPC and TCS DCS HSI are deployed in the main control room. This will involve removing some existing I\&C from the hard panels for the TCS and replacing legacy PPC displays and hardware elsewhere. This task is best accomplished during plant outage, as both systems are integral to plant operations. As such, the target date for final deployment of the PPC and TCS DCS HSI will likely need to be calibrated to correspond with a scheduled refueling outage at the plant.

With separate DCS backbone and DCS HSI deployments, the deployment of the DCS would logically span a period between two scheduled outages at the plant. It is, however, possible to compress this cycle. The DCS, including both the backbone and the HSI, may be deployed in a single setting. Alternately, portions of the DCS backbone may be installed piecemeal, without major obstruction to regular plant operations. 


\section{CONCLUSIONS}

The LWRS simulator in the HSSL is a unique facility that represents a full-scale control room simulator using glasstop technology. This facility enables the digital representation of existing analog control rooms in a manner that preserves the look and feel of the actual physical control room, while offering flexibility to support research into advanced digital technologies and modernized I\&C needed to support the transition of existing analog $I \& C$ technologies to digital replacements. Using 15 panels across 45 screens with touchscreen capability, the LWRS simulator faithfully replicates the look and functionality of analog I\&C panels used in conventional control rooms in NPPs. Driven by the same simulator models used in the plant training simulators, the simulator can be quickly reconfigured between different plants. In addition, as a dedicated research simulator, it can be modified to design, prototype, and validate DCS displays for control room modifications.

Under the LWRS Control Room Modernization project, the simulator has already been used to help two utilities modernize control rooms across three U.S. NPPs. This work is ongoing, but three key uses have emerged for the simulator:

- The LWRS simulator can serve as a standard testbed for control room modernization across the industry. The simulator incorporates a plant-neutral configuration based on glasstop panels that mimic current control panels. This design is especially suited to modernization efforts as plants make the transition from analog I\&C to hybrid control rooms incorporating DCS technology. This capability fills a crucial gap in existing research simulators, which are primarily used to develop workstationbased next generation control rooms. The transitional, hybrid phase has not previously had a dedicated research facility.

- The virtual nature of the glasstop simulators means that they can be more readily modified than the available training simulators at plants. Since no control or instrumentation is hardwired on the panels, changes may be easily made, and new designs may be iterated and tested to ensure they maintain and even enhance operator performance.

- The close mimic of existing plants means that validation exercises, such as integrated system validation, can be performed outside the training simulator. The challenge of making changes in the training simulator is that the simulator may for a time be forced offline to implement the changessomething that may not be possible due to the heavy training schedules required of licensed reactor operators. Moreover, changing the training simulator to reflect an updated control room establishes a difference between the actual control room and the training simulator. Such differences risk noncompliance with 10 CFR Part 55, "Operator's Licenses," Section 46, "Simulation Facilities," Subpart (d), "Continued assurance of simulator fidelity." By performing design, prototyping, and $\mathrm{V} \& \mathrm{~V}$ at a dedicated research simulator that is separate from the training simulator, it is possible to ensure minimal down time or time in which the training simulator differs significantly from the actual control room.

These three capabilities are not currently met by industry. Moreover, the LWRS mission to ensure these capabilities are broadly available and results widely disseminated poise the LWRS simulator to play a unique role in supporting the successful safe plant life extension of nuclear power plants.

The LWRS simulator has already been successful in its short existence. Future work will continue with the current approach, by:

- Incorporating additional plant simulator models to ensure that the lessons learned from control room modernization properly generalize across different reactors and plants in the U.S., 
- Deploying plant models from additional simulator vendors to ensure maximum reconfigurability and flexibility of the LWRS simulator,

- Facilitating innovative technology solutions (e.g., advanced alarm management systems and advanced DCS visualizations) to ensure that control room upgrades go beyond current limitations and improve plant safety and reliability, and

- Documenting the complete control room modernization process to augment existing guidance and provide a template that can benefit the utility and regulatory communities.

In addition, the simulator will transition to long-term II\&C research in which the focus is not solely on the technologies and process for control room modernization but in which the control room is an integral part of overall plant upgrades.

The newly completed HSSL glasstop simulator is a one-of-a-kind research facility that is being used to establish a systematic and rigorous approach to human factors engineering in the control room modernization process. This facility is poised to become an indispensible tool in developing new technologies for legacy control rooms in the nuclear industry. It is already a catalyst for control room upgrades, making possible design and validation that were previously difficult for industry to undertake. The time for control room modernization is upon the nuclear industry, and the HSSL simulator is helping to jumpstart a standardized and streamlined modernization process. As the immediate needs for control room modernization are met, this facility promises to be an equally powerful tool in plant-wide modernizations. 


\section{REFERENCES}

Boring, R.L., Agarwal, V., Joe, J.C., and Persensky, J.J. (2012). Digital Full-Scope Mockup of a Conventional Nuclear Power Plant Control Room, Phase 1: Installation of a Utility Simulator at the Idaho National Laboratory, INL/EXT-12-26367. Idaho Falls: Idaho National Laboratory.

Electrical Power Research Institute. (2005). Human Factors Guidance for Control Room and Digital Human-System Interface Design and Modification: Guidelines for Planning, Specification, Design, Licensing, Implementation, Training, Operation, and Maintenance, EPRI TR 1010042. Palo Alto: Electrical Power Research Institute.

Idaho National Laboratory. (2012). Human System Simulation Laboratory Program Plan, INL/MIS-1225017. Idaho Falls: Idaho National Laboratory.

Institute of Nuclear Power Operators. (1992). Survey of Nuclear Training Activity in US Electric Plants, INPO-92-007. Atlanta: Institute of Nuclear Power Operators.

International Standards Organization. (2010). Ergonomics of Human-System Interaction-Part 210: Human Centred Design for Interactive Systems, ISO 9241-201. Geneva: International Standards Organization.

International Standards Organization. (1998). Ergonomic Requirements for Office Work with Visual Display Terminals (VDTs) -Part 11: Guidance on Usability, ISO 9241-11. . Geneva: International Standards Organization.

Joe, J.C., Boring, R.L., and Persensky, J.J. (2012). Commercial utility perspectives on nuclear power plant control room modernization. 8th International Topical Meeting on Nuclear Power Plant Instrumentation, Control, and Human-Machine Interface Technologies (NPIC\&HMIT), 2039-2046.

O’Hara, J.M., Borwn, W.S., Lewis, P.M., and Persensky, J.J. (2002). Human-System Interface Design Review Guidelines, NUREG-0700, Rev. 2. Washington, D.C.: U.S. Nuclear Regulatory Commission.

O'Hara, J.M., Higgins, J.C., Fleger, S.A., and Pieringer, P.A. (2012). Human Factors Engineering Program Review Model, NUREG-0711. Washington, DC: U.S. Nuclear Regulatory Commission.

Skjerve, A.B., and Bye, A. (2011). Simulator-Based Human Factors Studies Across 25 Years: The History of the Halden Man-Machine Laboratory. London: Springer Verlag.

Thomas, K., and Hallbert, B. (2013). Long-Term Instrumentation, Information, and Control Systems (II\&C) Modernization Future Vision and Strategy, INL/EXT-11-24154, Rev. 2. Idaho Falls: Idaho National Laboratory.

Ulrich, T., Boring, R., Phoenix, W., DeHority, E., Whiting, T., Morrell, J., and Backstrom, R. (2012). Applying Human Factors Evaluation and Design Guidance to a Nuclear Power Plant Digital Control System, INL/EXT-12-26787. Idaho Falls: Idaho National Laboratory.

U.S. Nuclear Regulatory Commission. (2000). Guidance for Implementation of 10 CFR 50.59, Changes, Tests, and Experiments, Regulatory Guide 1.187. Washington, DC: U.S. Nuclear Regulator Commission.

U.S. Nuclear Regulatory Commission. (2006). Criteria for Use of Computers in Safety Systems of Nuclear Power Plants, Regulatory Guide 1.152, Revision 2. Washington, DC: U.S. Nuclear Regulator Commission. 